\title{
Cancer associated-fibroblast-derived exosomes in cancer progression
}

\author{
Chao Li ${ }^{1}$, Adilson Fonseca Teixeira ${ }^{2}$, Hong-Jian Zhu $^{2}$ and Peter ten Dijke ${ }^{1^{*}}$ (i)
}

\begin{abstract}
To identify novel cancer therapies, the tumor microenvironment (TME) has received a lot of attention in recent years in particular with the advent of clinical successes achieved by targeting immune checkpoint inhibitors (ICIs). The TME consists of multiple cell types that are embedded in the extracellular matrix (ECM), including immune cells, endothelial cells and cancer associated fibroblasts (CAFs), which communicate with cancer cells and each other during tumor progression. CAFs are a dominant and heterogeneous cell type within the TME with a pivotal role in controlling cancer cell invasion and metastasis, immune evasion, angiogenesis and chemotherapy resistance. CAFs mediate their effects in part by remodeling the ECM and by secreting soluble factors and extracellular vesicles. Exosomes are a subtype of extracellular vesicles (EVs), which contain various biomolecules such as nucleic acids, lipids, and proteins. The biomolecules in exosomes can be transmitted from one to another cell, and thereby affect the behavior of the receiving cell. As exosomes are also present in circulation, their contents can also be explored as biomarkers for the diagnosis and prognosis of cancer patients. In this review, we concentrate on the role of CAFs-derived exosomes in the communication between CAFs and cancer cells and other cells of the TME. First, we introduce the multiple roles of CAFs in tumorigenesis. Thereafter, we discuss the ways CAFs communicate with cancer cells and interplay with other cells of the TME, and focus in particular on the role of exosomes. Then, we elaborate on the mechanisms by which CAFs-derived exosomes contribute to cancer progression, as well as and the clinical impact of exosomes. We conclude by discussing aspects of exosomes that deserve further investigation, including emerging insights into making treatment with immune checkpoint inhibitor blockade more efficient.
\end{abstract}

Keywords: TME, CAFs, cancer cells, immune cells, exosomes, biomarkers

\section{Introduction}

Cancer is a genetic disease in which multiple mutations in genomic DNA drive uncontrolled proliferation and cell morphological changes. Although cancer can be divided into different types according to its location and cell types, most cancers share a series of common characteristics: self-sufficiency in growth signals, limitless replicative potential, increased metastasis and invasion, insensitivity to antigrowth signals, resistance to cell death, activating angiogenesis,

\footnotetext{
${ }^{*}$ Correspondence: p.ten_dijke@lumc.nl

${ }^{1}$ Oncode Institute and Department of Cell and Chemical Biology, Leiden University Medical Center, Leiden, Netherlands
}

Full list of author information is available at the end of the article metabolic reprogramming and escaping immune surveillance [1]. Importantly, the mutations that functionally inactivate tumor suppressor gene products or activate proto-oncogene products are key factors that drive tumorigenesis [2].

Cancers can be described as a never healing wounds due to the integration of cellular activities and the role of inflammation and cytokines $[3,4]$. The signaling pathways that initially are activated to repair the lesion are similar in both processes, i.e. cancer development and wound healing. The vital difference between cancers and wound healing is the sustainability and exacerbation of the signaling pathways in cancer cells and their microenvironment [5]. Cancer development is a very dynamic

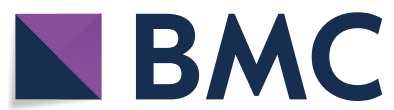

(c) The Author(s) 2021. Open Access This article is licensed under a Creative Commons Attribution 4.0 International License, which permits use, sharing, adaptation, distribution and reproduction in any medium or format, as long as you give appropriate credit to the original author(s) and the source, provide a link to the Creative Commons licence, and indicate if changes were made. The images or other third party material in this article are included in the article's Creative Commons licence, unless indicated otherwise in a credit line to the material. If material is not included in the article's Creative Commons licence and your intended use is not permitted by statutory regulation or exceeds the permitted use, you will need to obtain permission directly from the copyright holder. To view a copy of this licence, visit http://creativecommons.org/licenses/by/4.0/. The Creative Commons Public Domain Dedication waiver (http://creativeco mmons.org/publicdomain/zero/1.0/) applies to the data made available in this article, unless otherwise stated in a credit line to the data. 
and multistep process, and cells within a cancer are heterogeneous of which the (relative) composition changes during disease progression. Not only, is there communication between cancer cells within a tumor, but also between multiple cell types in the tumor microenvironment (TME) [6, 7]. The TME is composed of various cell types, including stromal cells (e.g. fibroblasts, mesenchymal stromal cells, pericytes, and adipocytes) and immune cells (e.g. T and B lymphocytes, natural killer (NK) cells and tumor-associated macrophages (TAMs)); all these cells are embedded in the extracellular matrix $(\mathrm{ECM})[8,9]$. While initially studies were focused on interfering with the malignant behavior of cancer cells for therapeutic intervention in cancer treatment, recently more research is geared towards the targeting of TME to find novel cancer therapies. In particular, immune therapy targeting immune checkpoint inhibitors (ICIs) has shown dramatic long-lasting beneficial effects, even on patients with metastatic disease [10]. However, immune therapy only works for about $15 \%$ of cancer patients [11]. Recently, a combination of ICIs with anti-angiogenic therapy has been developed to overcome the limitations of ICIs monotherapy, mainly by inhibiting angiogenesis and increasing the infiltration of cytotoxic $\mathrm{T}$ cells into the TME $[12,13]$. This combination strategy targeting on TME has demonstrated more clinical benefits and promising outcomes in many clinical trials [14].

Among the multiple stromal cell types in the TME, the cancer associated fibroblasts (CAFs) are a dominant component [15] of several cancer types including breast, colon, pancreatic and prostate cancers [16, 17]. In pancreatic cancer, $60-70 \%$ of tumor mass is composed of stromal tissue characterized by CAFs and excessive collagen and other ECM component deposition [16, 18]. CAFs are a highly heterogeneous cell type, some subtypes of which have cancer-restraining and others have cancer-promoting properties [19]. Also, CAFs can be divided into several subtypes according to their differential expression of specific biomolecular markers, and different subtypes exert different functions [20]. Fibroblasts are usually quiescent in normal tissues, but they can be activated during tissue damage [19]. These activated fibroblasts located in the vicinity of cancer cells are an important subtype of CAF population [21]. CAFs modulate cancer development through multiple aspects such as influencing cancer cell invasion and metastasis, promoting immune evasion, stimulating angiogenesis and promoting chemotherapy resistance [22-25]. In addition to ECM remodeling, CAFs can exert great impact on tumorigenesis through paracrine factors, such as cytokines and exosomes (see below).

The intercellular communication occurs via multiple ways, such as by direct cell-cell contact and by the transfer of secreted molecules or vesicles. Secretion of exosomes is an important way for CAFs to influence behavior of cancer cells (and vice versa). Exosomes are a subtype of extracellular vesicles (EVs), which originate from endosomal vesicles secreted by cells [26]. Most exosomes are small (s) EVs and have a diameter between $30 \mathrm{~nm}$ to $150 \mathrm{~nm}$ [27]. These sEVs contain proteins, nucleic acids and lipids that can be transferred from one cell to another, and thereby (in) activate signaling pathways [28]. Exosomes secreted from cancer cells, immune cells and other cell types in the TME also exert great impact on tumorigenesis. These aspects have been excellently summarized by others and will not be the focus of our review [29-33]. Here, we concentrate on the role of CAFs-derived exosomes in cancer progression. Our review is structured as follows: we first introduce the role of CAFs in cancer development and how CAFs communicate with others cells in TME. Then, we describe on how CAFs-derived exosomes regulate cancer cells and other cells of TME. At last, as exosomes inform the heterogeneous biological processes related to tumor growth and have a therapeutic potential [28], we discuss the clinical applications of exosomes, in particular within the context of making immune checkpoint therapy more effective.

\section{The role of CAFs in cancer progression within the TME What are CAFs?}

Fibroblasts act a critical role in connective tissues, maintaining tissue homeostasis by producing connective tissue ECM and different cytokines [34]. In healthy human tissues, they are usually quiescent as shown by their low levels of cell proliferation and metabolic activity [35]. Fibroblasts can be activated during tissue injury or inflammatory response, with enhanced cell proliferation and metabolic activity, including protein synthesis [36]. The activated fibroblasts observed in biological processes, such as wound healing and fibrosis, are called myofibroblasts, which express more fibroblast activation protein $\alpha$ (FAP) and $\alpha$-smooth muscle actin ( $\alpha$-SMA) and incorporate $\alpha$-SMA into cytoplasmic stress fibers [37, 38]. Compared with quiescent fibroblasts, myofibroblasts acquire contractile properties and secretory profiles that promote tissue repair during wound healing and cancer development [19].

CAFs are fibroblasts that are observed within the tumor microenvironment near cancer cells [15]. Generally, CAFs can be characterized through the expression of various mesenchymal markers, morphological features such as a spindle shape, and lack of expression of nonmesenchymal cell markers, such as markers for epithelial, endothelial, immune and neuronal cells. Activated CAFs 
are expected to express various marker proteins [25, 39], including $\alpha$-SMA, FAP, fibroblast-specific protein 1 (FSP1), podoplanin (PDPN) and platelet-derived growth factor receptor (PDGFR) [24, 40]. However, these markers are not unique to CAFs; they are also expressed in other cell types and healthy tissues. Currently, there is no single marker to identify all CAF-subtypes or to differentiate CAFs from other cell types [19].

In addition to distinguishing CAFs from other cell types, CAFs may also be subcategorized in different populations. Based on their resemblance with activated fibroblasts that are observed in non-malignant lesions, CAFs with high expression of $\alpha$-SMA are called myofibroblastic CAFs (myCAFs) [41]. However, CAFs are more heterogeneous than other fibroblasts and not all CAFs demonstrate elevated expression of $\alpha$-SMA. Combined to histologic techniques and fluorescence activated cell sorting (FACS) analysis, the emerging use of singlecell RNA sequencing (scRNA-seq) have added important information regarding CAFs heterogeneity. Whereas no specific biomarker was established so far, similar phenotypes have been described in different types of cancer, reinforcing their relevance as important players during cancer progression. In addition to myCAFs, the inflammatory CAF (iCAF) is another phenotype described in pancreatic cancer, which demonstrates low $\alpha$-SMA expression as opposed to classic "activated CAFs". iCAFs can release high levels of inflammatory cytokines such as interleukin-6 (IL-6), interleukin-11 (IL-11) and leukemia inhibitory factor (LIF) and lead to the immune suppression $[41,42]$. Similarly, the presence of CAFs with immunomodulatory function has also been demonstrated in breast cancers [43]. The immunosuppressive subset of CAFs (CAF-S1) described by Costa and collaborators was shown to recruit $\mathrm{T}$ lymphocytes and induce their differentiation towards CD25 antigen (CD25) High forkhead box P3 (FOXP3) High, which suggestively explains the accumulation of $\mathrm{FOXP}^{+} \mathrm{T}$ lymphocytes in some triple negative breast cancers. Subpopulations of CAFs distinguished by scRNA-seq were also described by $\mathrm{Li}$ et al. in colorectal cancer [44]. In this context, however, CAFs subpopulation were mainly distinguished according to the high expression of ECM remodeling-related genes (CAF-A) or cell motility-related genes (CAF-B). Interestingly, CAFs subpopulations may be characterized not only by different phenotypes, but also according to distinct spatial localization within the tumor mass. For instance, whereas myCAFs have been frequently reported adjacent to and in direct contact with cancer cells, most iCAFs seem to localize more distant from the cancer cells [37, 41].

Whereas CAFs localization within the tumor stroma may contribute to the existence of distinct subpopulations (e.g. myCAFs or iCAFs), CAFs differentiation from different progenitors may also account for their heterogeneity. Resident fibroblasts, bone marrowderived mesenchymal stem cells, epithelial cells following epithelial-to-mesenchymal transition (EMT), endothelial cells via endothelial-to-mesenchymal transition (EndMT), pericytes, adipocytes and other specialized mesenchymal cells such as stellate cells have all been described to originate CAFs [19, 23, 24, 45] (Fig. 1). Promisingly, the emerging scRNA-seq analysis of CAFs in different cancers will provide better biomarkers for the characterization of different subgroups of CAFs with distinct functions, especially for the CAFs with anti-tumor role and pro-tumorigenic role [42, 46-48]. The identification of specific markers for CAFs that act in an opposing manner in cancer progression may lead to improved CAF targeting for treatment of cancer patients.

\section{The functions of CAFs in cancer development}

CAFs can be functionally heterogenous with even opposing roles in cancer development. In most cases CAFs exert cancer-promoting functions, but also in some occasions anti-tumorigenic functions have been described $[15,39]$. The heterogeneity of CAFs also provide more challenges for CAFs targeting therapies, which requires the anti-CAFs therapeutic approaches should be more specific to the pro-tumorigenic CAFs [49].

\section{Anti-tumor roles of CAFs}

CAFs may exert tumor suppressor functions when they are activated by epithelial injury in the initial stages of cancer progression $[15,17,50]$. The activated fibroblasts contract the extracellular matrix so that the wound edges remain together, secrete matrix proteins to repair the remaining tissue injuries, and attract epithelial cells to complete the healing process [17]. Also, part of the CAF secretome may also have anti-tumor functions including transforming growth factor- $\beta$ (TGF- $\beta$ ), which can restrain tumor initiation in the early stage of carcinogenesis [51]. However, with the gradual growth of tumors, this repairing process may in turn switch and promote tumor growth, because cancer cells utilize the growth factors secreted by CAFs, to promote their survival and proliferation [15].

It is also possible that the anti-tumor role described for CAFs is restricted to specific subtypes of CAFs in particular cancer types. Specifically, Meflin was shown as a marker for anti-tumorigenic CAFs in pancreatic ductal adenocarcinoma (PDAC). Infiltration of Meflinpositive CAFs was associated with good prognosis for PDAC patients. In line with this notion, overexpression of Meflin in CAFs inhibited the tumor growth, whereas the loss of Meflin promoted the tumor progression in a 


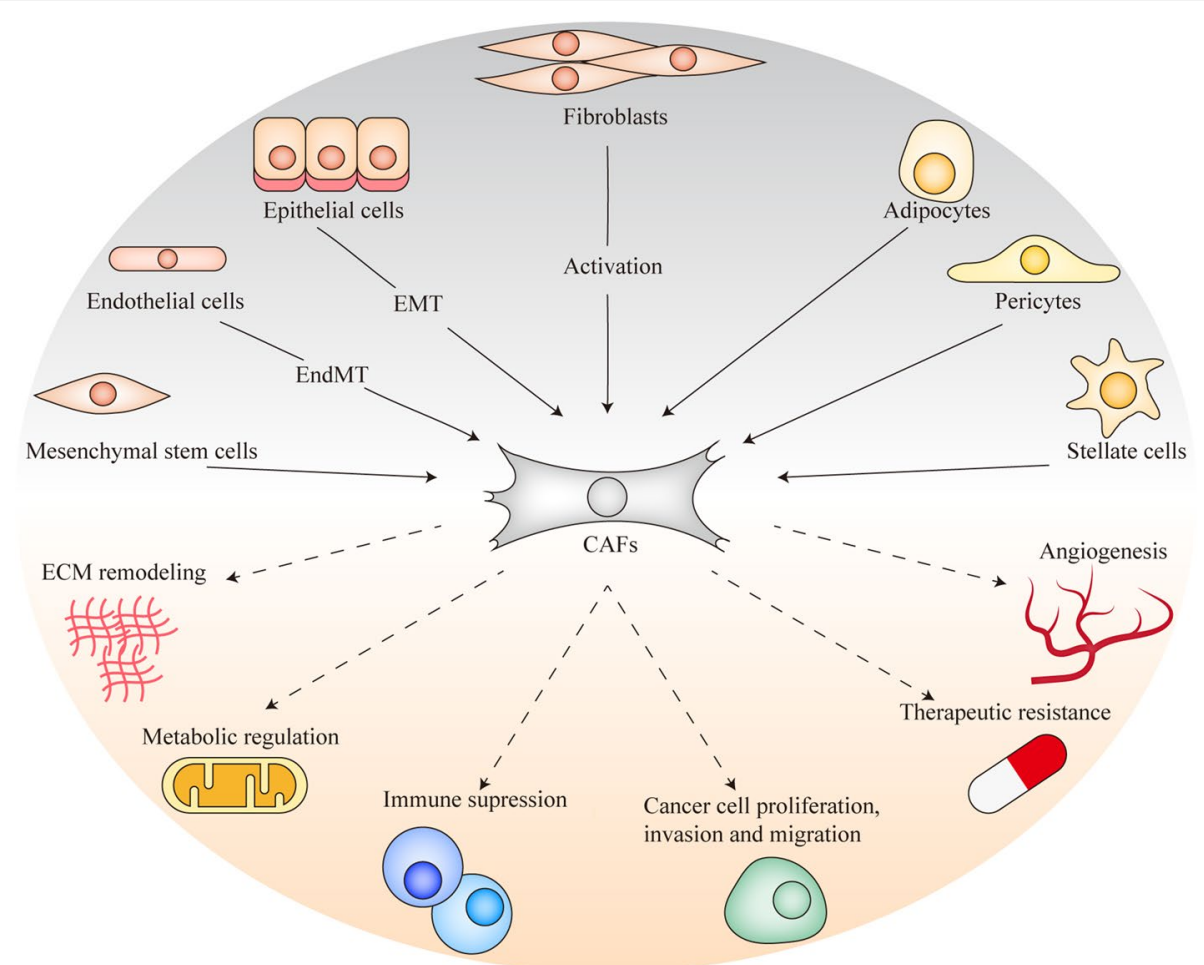

Fig. 1 The origins and functions of CAFs in cancer progression. In the TME, CAFs can originate from resident fibroblasts by activation, epithelial cells following EMT, endothelial cells via EndMT, bone marrow-derived mesenchymal stem cells, pericytes, adipocytes and hepatic stellate cells by trans-differentiation. In most cases CAFs have cancer-promoting functions. CAFs play an important role in ECM remodeling by secreting ECM components and enzymes. CAFs can not only serve as physical barriers to protect the cancer cells from the external drugs and the attack of immune cells, but also secrete abundant soluble factors, EVs and ECM to regulate other cells type in TME, which include stimulating cancer cell proliferation, invasion and migration, angiogenesis and therapy resistance. Moreover, CAFs can regulate cancer cell metabolism and stimulate immune evasion of cancer cells

PDAC mouse model [39]. Similarly, in another PDAC mouse model, the deletion of $\alpha-\mathrm{SMA}^{+} \mathrm{CAFs}$ was also shown to promote cancer progression by increasing the number of $\mathrm{CD}^{+}{ }^{+} \mathrm{Foxp}^{+}$regulatory $\mathrm{T}$ (Treg) cells in tumors, suggesting an important anti-tumor role for $\alpha-\mathrm{SMA}^{+}$CAFs in PDAC [52]. In estrogen receptor (ER) positive breast cancer, CAFs can be divided into two subtypes with opposite functions based on CD146 expression. The CD146-positive CAFs have been proved to maintain ER expression in ER positive breast cancer cells and remain estrogen responsive and sensitivity to tamoxifen, while CD146-negative CAFs can inhibit the response of cancer cells to tamoxifen and lead to poor treatment outcomes [53]. Besides, the versican (VCAN) is also a potential marker for the tumor-repressing CAFs. The depletion of VCAN in QRsP11 murine fibrosarcoma cells was demonstrated to promote tumor growth and angiogenesis in the mouse model. Specially, the loss of VCAN in QRsP11 cells inhibited collagen biosynthesis and proliferation of fibroblasts, and then reduce the collagen stiffness [54]. This dysregulation of the ECM structure may facilitate the sprouting of endothelial cells and tube formation toward angiogenesis. Based on these studies, the non-selective targeting of whole CAF population maybe not efficient for all cancer types. More reliable and specific markers for anti-tumor CAFs in different cancers remain to be discovered to improve the precision of targeting treatment [55].

\section{Pro-tumorigenic roles of CAFs}

CAFs can promote cancer development in multiple aspects, including stimulating cell proliferation, invasion and migration of cancer cells, angiogenesis and therapy resistance. CAFs can also regulate immunity and metabolism to promote tumorigenesis through secreting cytokines, chemokines, EVs and the ECM $[15,36,56]$ (Fig. 1).

Promoting the proliferation, invasion and migration of cancer cells is a major way of CAFs to facilitate the cancer development. Cytokines secreted by CAFs that have been implicated in this process include TGF- $\beta$, interleukin- $1 \alpha$ (IL-1 $\alpha$ ), IL-6, interleukin-33 (IL-33), stromal cell-derived 
factor 1 (SDF1), C-X-C motif chemokine ligand 8 (CXCL8) and cyclooxygenase-2 (COX-2) [15, 57-61], and different molecules mediate diverse effects. For example, secretion of TGF- $\beta$ by CAFs promotes the EMT of breast cancer cells via TGF- $\beta /$ SMAD and non-SMAD signaling pathways [62,63], and facilitates the tumor growth and metastasis in colorectal cancer [64, 65]. It is noteworthy that secretions of certain cytokines by CAFs, such as TGF- $\beta$, can cause a positive feedback loop that leads to a prolonged CAF overactivation [37]. Importantly, CAFs also promote the invasion of cancer cells through forming invadopodia and secreting matrix metalloproteinases (MMPs) to degrade the surrounding ECM [56].

In addition, the initiation of tumor vascularization provides an environment that enables rapid tumor growth and facilitates metastasis [66]. Vascular endothelial growth factor (VEGF) is a pivotal factor secreted by CAFs to stimulate new vessel formation, which can be increased by other extracellular cues, such as hypoxia [67]. Other examples of pro-angiogenic factors produced by CAFs are Wnt family member 2 (WNT2), TGF- $\beta$, MMPs, fibroblast growth factors (FGFs), angiopoietin-1 and angiopoietin-2 $[68,69]$.

CAFs play a crucial part in immunosuppression by producing multiple cytokines, such as TGF- $\beta$, IL-6, SDF-1, $\mathrm{C}$-X-C motif chemokine ligand 5 (CXCL5) and C-X-C motif chemokine ligand 12 (CXCL12) [36, 70]. Macrophages are the main leukocytes infiltrating solid tumor tissues [71]. CAFs can induce macrophages to polarize from pro-inflammatory M1 into a resolving inflammation M2-like phenotype in pancreatic cancer and prostate cancer [72]. The M2 phenotype is the TAM phenotype promoting EMT and invasion of cancer cells. CAFsderived IL-6, SDF-1 and macrophage colony-stimulating factor (M-CSF) have been reported to involved in M2 macrophage polarization [73, 74]. Besides, immune cells such as $\mathrm{T}$ cells and NK cells can be functionally suppressed by CAFs, by secretion of programmed cell death 1 (PD-1), programmed cell death 2 (PD-2), CXCL5 and prostaglandin E2 (PGE2) $[75,76]$.

CAFs can modulate the metabolism of cancer cell in multiple ways. Cancer cells were found to undergo metabolic reprogramming and increase aerobic glycolysis to produce ATP even in normal oxygen levels, which was known as the Warburg effect $[77,78]$. The similar phenomenon can also happen in CAFs [79]. The CAFs undergo aerobic glycolysis and secret energy metabolites including lactate and pyruvate to the adjacent cancer cells, which enhance the ATP production and increase cancer cell proliferation [79-81]. This metabolic symbiosis phenomenon is termed as Reverse Warburg effect. Furthermore, the loss of caveolin-1 (Cav-1) in CAFs can increase the expression of glycolytic enzymes and promote tumor growth and angiogenesis, which has been proposed as biomarker for the Reverse Warburg effect [79, 82, 83]. In addition, ECM components produced by $\mathrm{CAFs}$ and $\mathrm{CAFs}$-derived cytokines including $\mathrm{C}-\mathrm{C}$ motif chemokine ligand 5 (CCL5), IL6, and C-X-C motif chemokine ligand 10 (CXCL10) were found to regulate cancer cell metabolism by impacting on different signaling pathways [84-86].

The therapy resistance of tumors is also linked to CAF activation. CAFs not only provide a physical barrier by increased interstitial fluid pressure that impedes therapeutic drugs from reaching cancer cells, but also by secreting various proteins and cytokines that can attenuate the efficiency of chemotherapy. For example, SDF-1 secreted by CAFs triggered malignant progression and gemcitabine resistance in pancreatic cancer by enhancing the expression of special AT-rich sequence-binding protein-1 (SATB-1) in cancer cells [57].

\section{The communication between CAFs and other cells}

As mentioned before, the interplay between CAFs and other cells favors cancer progression by mediating, for example, cancer cell proliferation, invasion, and immune evasion. Within the TME, this interplay occurs via multiple different modes of action. Cross-talk between CAFs and other cells can be mediated by direct cell-to-cell contact or indirect communication. The direct cell-tocell contact can involve gap junctions, tunneling nanotubes, direct transmembrane ligands interacting with transmembrane receptors, and adhesion molecules. Conversely, the indirect interaction relies on secreted cytokines, growth factors, chemokines, peptides, amino acids and EVs [87, 88], which can act over short or long distances. Moreover, CAFs efficiently change the ECM constitution. Further interaction between cell surface proteins and ECM molecules plays an important role on cancer progression and therefore might also be considered an important mechanism for the crosstalk between CAFs and other cell types within the TME (Fig. 2).

Although different strategies greatly contribute for the crosstalk between distinct cell types within a tumor, the next sections dedicate a special attention to the indirect interaction between CAFs and other cells. Among the mechanisms that may be used in this process, an interesting part has recently emerged for exosomes and their role is then discussed as critical mediators of cargo transference from CAFs to other cells within the tumor stroma.

\section{Cell-cell junctions}

Several mechanisms enable the transference of cellular cargos from CAFs to cancer cells and vice versa. Cell-cell junctions play an important role mediating the interaction between these cells upon direct cell contact. 


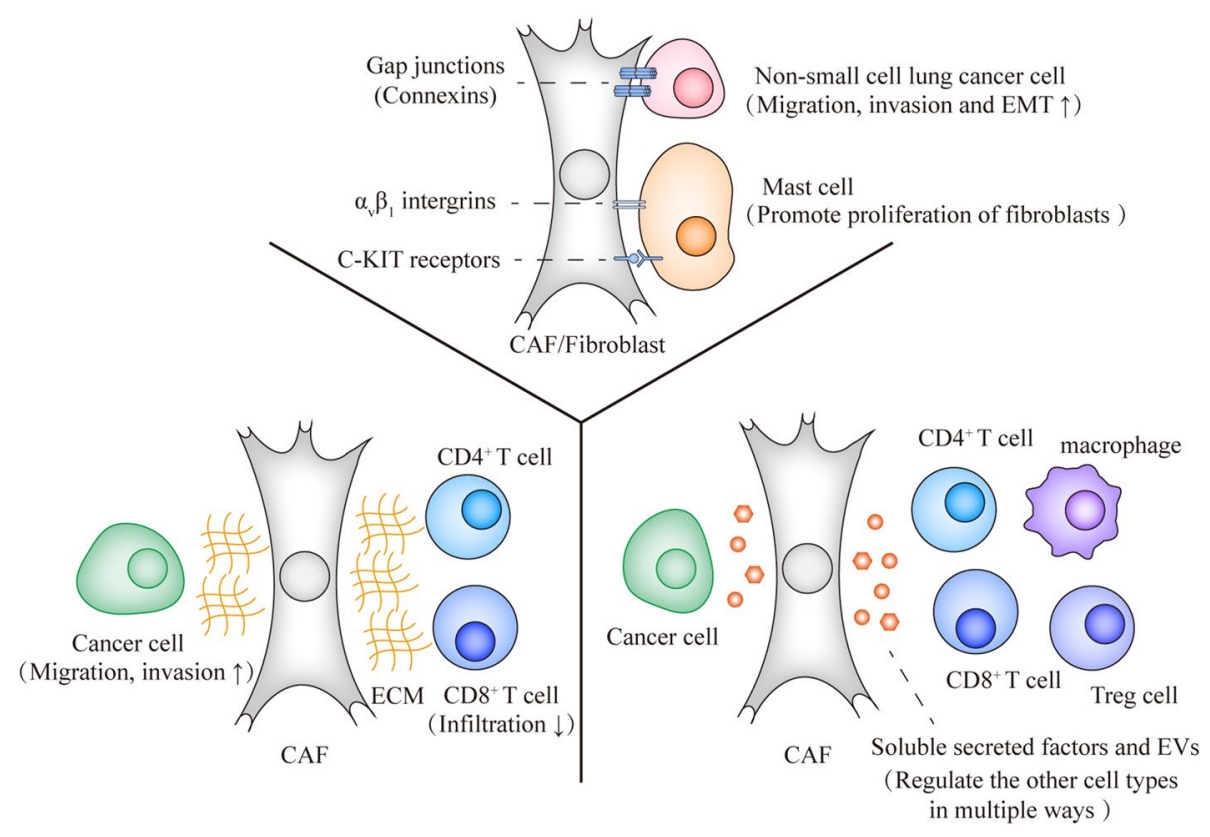

Fig. 2 The communication ways between CAFs and other cells. Examples are depicted of the different manners of cross-talk between CAFs and other cell types; they can be mainly divided into three groups: (i) cell-to-cell junctions, (ii) ECM interactions and (iii) the interactions mediated by secreted cytokines, growth factors, chemokines, peptides, amino acids and EVs, including exosomes

For example, the intercellular space of gap junctions is between 2 and $4 \mathrm{~nm}$, while tunneling nanotubes are $50-100 \mu \mathrm{m}$ in length $[89,90]$. Specifically, gap junctions that consist of six connexins, mediate gap junctional intercellular communication (GJIC) by physical contacts between CAFs and other cells. They are able to mediate the transfer of rather small molecules and metabolites that are up to $1000 \mathrm{Da}$ [91]. For instance, in non-small cell lung cancer (NSCLC), connexin 43 (Cx43)-formed unidirectional GJIC was found to play an important role in regulating metabolic cooperation between NSCLC cells and CAFs. CAFs undergo aerobic glycolysis (i.e., the Reverse Warburg effect) in TME as mentioned before. CAFs undergoing aerobic glycolysis can enhance the OXPHOS of NSCLC cells by transferring tricarboxylic acid (TCA) metabolites, including ATP, to NSCLC cells through Cx43-formed unidirectional GJIC. Therefore, this process can activate the phosphatidylinositol 3-kinase/protein kinase B (PI3K/AKT) and mitogen-activated protein kinases/extracellular signal-regulated kinase (MAPK/ERK) signaling pathways in NSCLC cells. These effects promote migration, invasion and EMT of NSCLC cells [92]. Similarly, adjacent cells can communicate with each other via contact-dependent signaling like ligand-receptor pairs and other ways of cell adhesion. For example, $\alpha_{\mathrm{v}} \beta_{1}$ integrins and c-KIT receptors on the cells surface of HMC-1 mast cells can mediate the attachment to fibroblasts in chronically inflamed tissues [93, 94].
The release of interleukin-4 (IL-4) by mast cells induced by heterotypic cell-cell adhesion between mast cells and fibroblasts is an important stimulation of fibroblast proliferation $[93,95,96]$.

\section{ECM interactions}

CAFs can indirectly affect cancer cell behavior and other cell types in the TME by secreting ECM proteins and remodeling the ECM. ECM proteins including integrins, matricellular proteins, structural ECM proteins (collagen, fibronectin) and metalloproteinases that can serve as signaling mediators between fibroblasts and cancer cells [97]. The production of these ECM components can remodel the ECM and affect their organization, including ECM stretching, crosslinking, aligning, bundling, and stiffening [56]. CAFs can also degrade the ECM through secreting specific proteases such as MMPs [98]. Certain ECM modifications, such as high contractility, are a feature when fibroblasts transform into CAFs. CAFs can remodel the ECM and create the paths for cancer cells to migrate [99], and thereby facilitate cancer cell invasion. For example, FAP was shown to be highly expressed in CAFs rather than cancer cells and normal tissue in pancreatic cancer. The overexpression of FAP in CAFs can organize fibronectin and collagen I fibers into parallel orientation, which can elevate directionality and velocity of cancer cells in the ECM [100]. Besides, ECM also play a crucial role in the regulation of immune cell 
trafficking. For instance, the decrease of hyaluronan and proteoglycan link protein 1 (HAPLN1) in aged fibroblasts was shown to lead to less contractile ECM that impeded the infiltration $\mathrm{CD}^{+}{ }^{+}$and $\mathrm{CD}^{+}{ }^{+} \mathrm{T}$ cells, and promoted metastasis of melanoma cells [101].

\section{Soluble secreted factors}

CAFs are a substantial source of cytokines, chemokines, growth factors and other secreted factors in the TME. One of the most studied CAFs-secreted cytokines is TGF- $\beta$, whose pathway is crucial in promoting tumor progression in various cancer subtypes [34]. TGF- $\beta$ and other growth factors and chemokines released by CAFs also act on different types of immune cells including $\mathrm{CD}^{+} \mathrm{T}$ cells, Treg cells and macrophages with mostly immune-suppressive consequences [36, 102]. Besides, the metabolites and amino acids secreted by CAFs is another way that mediate the communication between stromal fibroblasts, tumor cells and other cell types in TME [86, 103, 104]. For instance, through the provision of alanine, CAFs further enhance carcinogenesis by allowing cancer cells to fuel the TCA cycle, support lipid and non-essential amino acids (NEAA) synthesis, as well as diverting glucose metabolism to serine and glycine synthesis, both of which are essential for cancer cell survival [105].

\section{Extracellular vesicles}

Besides releasing soluble factors, secreting EVs is a critical determinant to enable autocrine and paracrine signals that promote cancer cell aggressiveness and therapy resistance. The classification of EVs has been updated during recent years and new insights continue to be obtained. According to the Minimal information for studies of extracellular vesicles 2018 (MISEV2018) guidelines, as proposed by the International Society for Extracellular Vesicles (ISEV), the EVs are classified into different subtypes according to the physical characteristics. For example, the size is a commonly used standard to distinguish different subtypes of EVs. The diameter of small EVs (sEVs) is below $100 \mathrm{~nm}$ or $200 \mathrm{~nm}$, while the diameter of medium/large EVs ( $\mathrm{m} / \mathrm{lEVs}$ ) is more than $200 \mathrm{~nm}$. EVs can also be classified based on other physical characteristics, including density (low, middle, high, with ranges defined), biochemical composition with specific makers such as $\mathrm{CD} 63^{+} / \mathrm{CD} 81^{+} \mathrm{EVs}$, and origins or conditions such as apoptotic bodies [106]. Historically, exosomes is another widely used definition for a specific subpopulation of sEVs, which range from $30-150 \mathrm{~nm}$ and originate from endosomes [27, 28]; vesicles with these properties, termed exosomes have been indicated to play a critical part in physiological and pathological processes [107-109]. In the TME, CAFs are a notable source of exosomes [110].
Exosome biogenesis mainly comprises three different stages, including (a) the formation of endocytic vesicles via invagination of the plasma membrane called early endosome; (b) the formation of multi-vesicular bodies (MVBs) containing intraluminal vesicles (ILVs) generated by inward budding of the endosomal membrane with the cytoplasmic constituents; and (c) the fusion of MVBs with the plasma membrane and extracellular release of ILVs as exosomes [28, 111, 112] (Fig. 3). Also, the MVBs can be degraded through fusing with lysosomes or autophagosomes [113]. A multitude of proteins are involved in the maturation of MVBs and ILVs, including endosomal sorting complex required for transport (ESCRT) proteins which consist of four different protein complexes, ESCRT-0, -I, -II, and -III [28, 114, 115]. In addition to ESCRT proteins, apoptosis-linked gene 2-interacting protein X (ALIX) [116], vesicle trafficking 1 (VTA1) [117], soluble N-ethylmaleimide-sensitive factor attachment protein receptor (SNARE) [118] and GTPases are also considered as important players in exosome biogenesis and secretion [119].

After secretion, exosomes are taken up by neighboring cells via endocytosis or by fusion with the plasma membrane [120, 121]. After internalization, exosomes can be degraded by lysosomes in recipient cells. Also, the internalized exosomes may fuse with endosomes, and then disintegrate and release vesicle contents into the cytoplasm or fuse back with the plasma membrane and release exosomes to the outside of recipient cells [113, 122-124].

Exosomes are highly heterogeneous, which is reflected in differences in their sizes and contents [113]. With respect the later, cellular origin and signaling from extracellular environment have great impact on heterogeneity. Exosomes are composed of metabolites, lipids, functional proteins including membrane proteins, cytosolic and nuclear proteins, extracellular matrix proteins, and nucleic acids including mRNAs, noncoding RNAs, and DNA fragments $[113,125,126]$. The contents of exosomes are important regulators of cellular functions and pathological states, such as tumorigenesis, immune responses, inflammatory reactions and cell death [113]. In TME, CAFs-derived exosomes also regulate tumor growth, metastasis, angiogenesis, and mediate therapy resistance of tumor cells [110].

\section{The role of exosomes secreted by CAFs on other cells in the TME}

The impact of CAFs-derived exosomes on cancer cells

The secretion of exosomes is an important way of CAFs to influence cancer cell behavior [110, 127]. Consistent with this notion, CAFs-derived exosomes have been associated with several hallmarks of cancer. The abnormal 


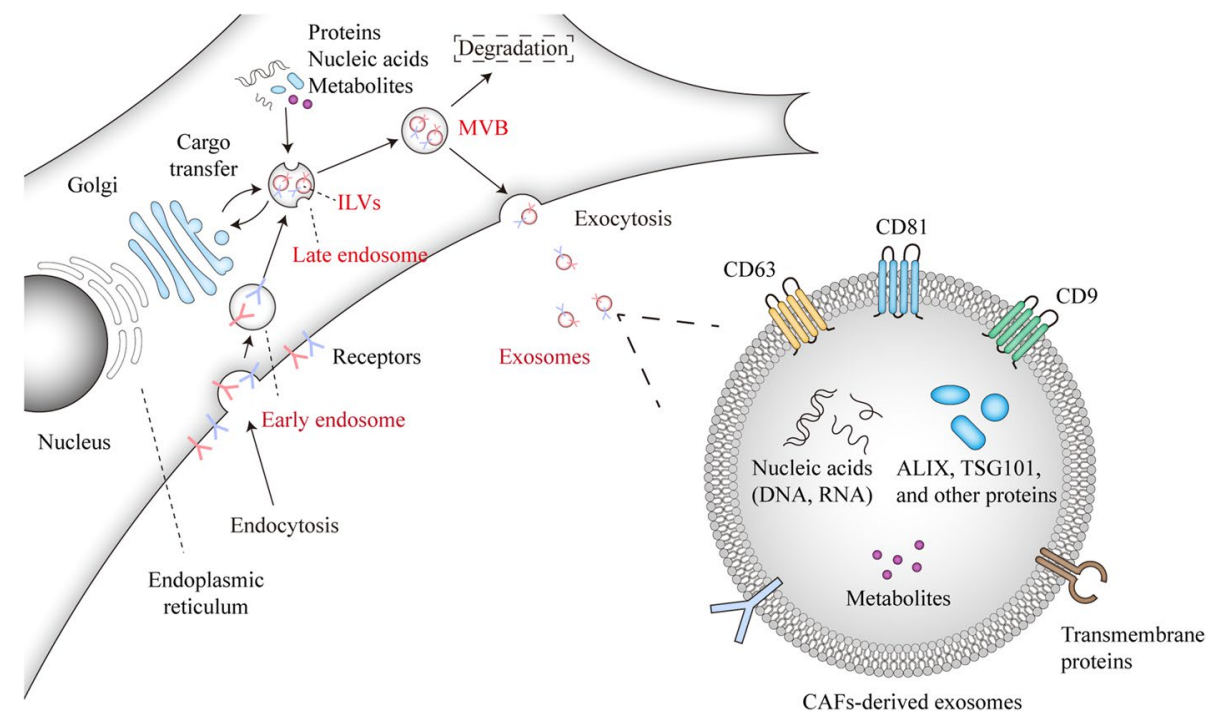

Fig. 3 Schematic presentation of exosomes in the TME. The biogenesis of exosomes mainly comprises three stages, which includes (i) the formation of early endosome by cytoplasmic membrane invagination, (ii) the formation of MVBs containing cargos-enriched ILVs, and (iii) the release of ILVs as exosomes after the fusion of MVBs with the plasma membrane

expression of molecules contained in the CAFs-derived exosomes can lead to the dysregulation of signaling pathways in cancer cells after the uptake of exosomes by cancer cells (Table 1). Also, these dysregulated molecules including non-coding RNAs in the CAFs-derived exosomes are potential biomarkers for the specific cancer types.

\section{Proliferation, migration and invasion}

Although the role of CAFs-derived exosomes in cancer development is likely dynamic and specific to cancer type, genetics and stage, the CAFs-derived exosomes can affect the proliferation, migration and invasion of cancer cells. Exosomal microRNAs (miRNAs) were shown to have important functions in the crosstalk between CAFs and cancer cells. Numerous CAF-derived exosomal miRNAs have been identified and shown to play a pivotal role in cancer development. For examples, miR-181d-5p, miR-500a-5p, miR-21, miR-22, miR-378e and miR-143 were found to be upregulated in breast CAFs-derived exosomes compared exosomes secreted by normal fibroblasts [129, 131, 133, 134]. In breast cancer, CAFsderived exosomes carrying miR-181d-5p can promote proliferation, invasion, migration, and EMT and inhibit apoptosis of cancer cells by targeting caudal-related homeobox 2 (CDX2) and then downregulating CDX2 and its downstream gene -homeobox A5 (HOXA5) [129]. Besides, the exosomal miR-500a-5p can promote breast cancer cell proliferation and metastasis by targeting and reducing the expression of ubiquitin-specific peptidase
28 (USP28) [133]. In addition, some circular RNAs (circRNAs) were also found to have tumor-promoting roles in CAFs-derived exosomes. Specifically, the level of exosomal circHIF1A derived from hypoxic CAFs was increased compared to the normoxic CAFs in breast cancer. The circHIF1A can act as a sponge for miR-580-5p and decrease the level of miR-580-5p, which was shown to target the CD44 molecule (CD44) mRNA and decrease the expression of CD44. In this way, the up-regulated circHIF1A from CAFs-derived exosome in hypoxia can boost the expression of CD44 indirectly, and then enhance the cancer stem cell plasticity in TME [135]. In colorectal cancer, CAF-secreted exosomal circEIF3K was shown to inhibit cancer cell proliferation, invasion and tube formation in vitro, suggestively by targeting miR-214 and impairing its activity [141]. Similar to miRNAs and circRNAs, the secretion of long noncoding RNAs (lncRNAs), via CAFs exosomes have been proved to have cancer-promoting abilities. In colorectal cancer, for example, LINC00659 can be delivered from CAFs to cancer cells via exosomes. The up-regulated LINC00659 interacts directly with miR-342-3p, and increases Annexin A2 (ANXA2) expression in CRC cells. The latter promotes CRC cell proliferation, migration, invasion and EMT progression in vitro [138]. On the other hand, many miRNAs that are down-regulated in CAFs-derived exosomes compared with normal fibroblasts-derived exosomes also have the link with cancer progression. MiR-148b and miR-320a are expressed at lower levels in endometrial cancer cells and CAFs compared to normal cells, 
Table 1 The role of cargos in CAFs-derived exosomes on regulating the cancer cells

\begin{tabular}{|c|c|c|c|c|c|}
\hline Cancer type & Molecule in exosomes & Expression & Mechanism & Impact on cancer cells & Ref \\
\hline Bladder cancer & miR-148b-3p & Up-regulated & $\begin{array}{l}\text { Target PTEN and activate } \\
\text { Wnt/ } \beta \text {-catenin pathway }\end{array}$ & $\begin{array}{l}\text { Promote tumor proliferation, } \\
\text { metastasis and drug resistance }\end{array}$ & [128] \\
\hline \multirow[t]{7}{*}{ Breast cancer } & miR-181d-5p & Up-regulated & $\begin{array}{l}\text { Target CDX2 and downregu- } \\
\text { late CDX2 and HOXA5 }\end{array}$ & $\begin{array}{l}\text { Enhance the aggressiveness of } \\
\text { breast cancer }\end{array}$ & [129] \\
\hline & SNHG3 (IncRNA) & Up-regulated & $\begin{array}{l}\text { Target miR-330-5p and } \\
\text { increase the PKM expression }\end{array}$ & Increase glycolysis metabolism & [130] \\
\hline & miR-21, miR-378e, miR-143 & Up-regulated & Not mentioned & $\begin{array}{l}\text { Induce of the stemness and } \\
\text { EMT phenotype of breast } \\
\text { cancer }\end{array}$ & [131] \\
\hline & ADAM10 & Up-regulated & $\begin{array}{l}\text { Activate RhoA and Notch } \\
\text { signaling }\end{array}$ & $\begin{array}{l}\text { Promote cells motility and } \\
\text { tumor progression }\end{array}$ & [132] \\
\hline & miR-500a-5p & Up-regulated & $\begin{array}{l}\text { Target USP28 and downregu- } \\
\text { late USP28 }\end{array}$ & $\begin{array}{l}\text { Promoted the proliferation } \\
\text { and metastasis of breast } \\
\text { cancer cells }\end{array}$ & [133] \\
\hline & miR-22 & Up-regulated & $\begin{array}{l}\text { Target ESR1 and PTEN, and } \\
\text { downregulate ESR1 and PTEN. }\end{array}$ & Promote tamoxifen resistance & [134] \\
\hline & circHIF1A & Up-regulated & $\begin{array}{l}\text { Increase the expression of } \\
\text { CD44 by targeting and down- } \\
\text { regulating miR-580-5p }\end{array}$ & $\begin{array}{l}\text { Promote breast cancer cells } \\
\text { proliferation and stemness in } \\
\text { hypoxic stress }\end{array}$ & [135] \\
\hline (Triple-negative breast cancer) & miR-4516 & Down-regulated & $\begin{array}{l}\text { Target FOS like antigen } 1 \\
\text { (FOSL1) }\end{array}$ & $\begin{array}{l}\text { Promote the development of } \\
\text { TNBC }\end{array}$ & [136] \\
\hline \multirow[t]{5}{*}{ Colorectal cancer } & H19 (IncRNA) & Up-regulated & $\begin{array}{l}\text { Activate the } \beta \text {-catenin } \\
\text { pathway }\end{array}$ & $\begin{array}{l}\text { Promote the stemness of } \\
\text { cancer stem cells }\end{array}$ & [137] \\
\hline & LINC00659 & Up-regulated & $\begin{array}{l}\text { Target miR-342-3p and down- } \\
\text { regulate miR-342-3 }\end{array}$ & $\begin{array}{l}\text { Promote cancer cells prolifera- } \\
\text { tion, invasion, migration and } \\
\text { EMT progression }\end{array}$ & [138] \\
\hline & miR-590-3p & Up-regulated & $\begin{array}{l}\text { Target CLCA4 and downregu- } \\
\text { late CLCA4 }\end{array}$ & $\begin{array}{l}\text { Promote radiotherapeutic } \\
\text { resistance }\end{array}$ & [139] \\
\hline & circSLC7A6 & Up-regulated & $\begin{array}{l}\text { Increase the expression of } \\
\text { C-X-C motif chemokine recep- } \\
\text { tor } 5 \text { (CXCR5) }\end{array}$ & $\begin{array}{l}\text { Promote cancer cells prolifera- } \\
\text { tion and metastasis }\end{array}$ & [140] \\
\hline & circEIF3K & Up-regulated & $\begin{array}{l}\text { Increase the expression of } \\
\text { programmed death-ligand } \\
1 \text { (PD-L1) by targeting and } \\
\text { downregulating miR-214 }\end{array}$ & $\begin{array}{l}\text { Promote hypoxia-induced CRC } \\
\text { progression }\end{array}$ & [141] \\
\hline \multirow[t]{2}{*}{ Endometrial cancer } & miR-148b & Down-regulated & $\begin{array}{l}\text { Target DNMT1 and downregu- } \\
\text { late DNMT1 }\end{array}$ & $\begin{array}{l}\text { Promote cancer cells metasta- } \\
\text { sis by inducing EMT }\end{array}$ & [142] \\
\hline & miR-320a & Down-regulated & $\begin{array}{l}\text { Target HIF1a and downregu- } \\
\text { late HIF1a }\end{array}$ & $\begin{array}{l}\text { Promote cancer cells prolifera- } \\
\text { tion }\end{array}$ & [143] \\
\hline \multirow[t]{2}{*}{ Esophageal cancer } & miR-33, miR-326 & Up-regulated & Not mentioned & $\begin{array}{l}\text { Promote CAF phenotype and } \\
\text { tumor progression }\end{array}$ & [144] \\
\hline & $\mathrm{SHH}$ & Up-regulated & $\begin{array}{l}\text { Activate } \mathrm{SHH} \text { signaling } \\
\text { pathway }\end{array}$ & $\begin{array}{l}\text { Improve the growth and } \\
\text { migration abilities }\end{array}$ & [145] \\
\hline \multirow[t]{2}{*}{ Gastric cancer } & miR-522 & $\begin{array}{l}\text { Up-regulated } \\
\text { (Conditional) }\end{array}$ & $\begin{array}{l}\text { Target arachidonate lipoxyge- } \\
\text { nase } 15 \text { (ALOX15) and down- } \\
\text { regulate ALOX15 }\end{array}$ & $\begin{array}{l}\text { Inhibit ferroptosis in cancer } \\
\text { cells }\end{array}$ & [146] \\
\hline & circ_0088300 & Up-regulated & $\begin{array}{l}\text { Enhance janus kinase } 1 / \text { signal } \\
\text { transducer and activator of } \\
\text { transcription } 1 \text { (JAK1/STAT1) } \\
\text { signaling pathway by targeting } \\
\text { miR-1305 and downregulating } \\
\text { miR-1305 }\end{array}$ & $\begin{array}{l}\text { Promote cancer cells prolifera- } \\
\text { tion, migration and invasion }\end{array}$ & [147] \\
\hline Head and neck cancer & miR-3188 & Down-regulated & $\begin{array}{l}\text { Target } B C L 2 \text { apoptosis regula- } \\
\text { tor (BCL2) and downregulate } \\
\text { BCL2 }\end{array}$ & Promote cancer cells growth & [148] \\
\hline Hepatocellular carcinoma & miR-320a & Down-regulated & $\begin{array}{l}\text { Target PBX homeobox } 3 \text { (PBX3) } \\
\text { and downregulate PBX3 }\end{array}$ & $\begin{array}{l}\text { Promote cancer cells prolifera- } \\
\text { tion and metastasis }\end{array}$ & [149] \\
\hline Lung cancer & SNAI1 & Up-regulated & Not mentioned & Promote EMT in cancer cells & [150] \\
\hline
\end{tabular}


Table 1 (continued)

\begin{tabular}{|c|c|c|c|c|c|}
\hline Cancer type & Molecule in exosomes & Expression & Mechanism & Impact on cancer cells & Ref \\
\hline \multirow[t]{3}{*}{ Oral squamous cell carcinoma } & miR-34a-5p & Down-regulated & $\begin{array}{l}\text { Target } A X L \text { receptor tyrosine } \\
\text { kinase }(A X L) \text { and downregu- } \\
\text { late } A X L\end{array}$ & $\begin{array}{l}\text { Promote cancer cells prolifera- } \\
\text { tion and metastasis }\end{array}$ & {$[151]$} \\
\hline & miR-382-5p & Up-regulated & Not mentioned & $\begin{array}{l}\text { Promote cancer cells migra- } \\
\text { tion and invasion }\end{array}$ & {$[152]$} \\
\hline & miR-21-5p & Up-regulated & $\begin{array}{l}\text { Enhance PI3K/mTOR/STAT3 } \\
\text { Signaling }\end{array}$ & $\begin{array}{l}\text { Promote normal gingival } \\
\text { fibroblasts (NGFs) to CAFs }\end{array}$ & {$[153]$} \\
\hline $\begin{array}{l}\text { Oral tongue squamous cell } \\
\text { carcinoma }\end{array}$ & MFAP5 & Up-regulated & $\begin{array}{l}\text { Activate MAPK and AKT } \\
\text { pathways }\end{array}$ & $\begin{array}{l}\text { Activate cancer cells growth } \\
\text { and migration }\end{array}$ & {$[154]$} \\
\hline Osteosarcoma & miR-1228 & Up-regulated & $\begin{array}{l}\text { Target suppressor of cancer } \\
\text { cell invasion (SCAI) and down- } \\
\text { regulate SCAI }\end{array}$ & $\begin{array}{l}\text { Promote osteosarcoma inva- } \\
\text { sion and migration }\end{array}$ & {$[155]$} \\
\hline \multirow[t]{2}{*}{ Ovarian cancer } & miR-98-5p & Up-regulated & $\begin{array}{l}\text { Target cyclin dependent } \\
\text { kinase inhibitor } 1 \mathrm{~A}(\mathrm{CDKN} 1 \mathrm{~A}) \\
\text { and downregulate CDKN1A }\end{array}$ & Promote cisplatin resistance & {$[156]$} \\
\hline & TGF- $\beta$ & Up-regulated & $\begin{array}{l}\text { Activate the SMAD signaling } \\
\text { pathway }\end{array}$ & $\begin{array}{l}\text { Promote migration and inva- } \\
\text { sion ability of cancer cells and } \\
\text { EMT }\end{array}$ & {$[157]$} \\
\hline Prostate cancer & miR-423-5p & Up-regulated & $\begin{array}{l}\text { Target GREM2 and downregu- } \\
\text { late GREM2 }\end{array}$ & $\begin{array}{l}\text { Promote chemotherapy } \\
\text { resistance }\end{array}$ & {$[158]$} \\
\hline
\end{tabular}

and their expression is also reduced in CAFs-derived exosomes compared to normal fibroblasts-derived exosomes. The miR-148b and miR-320a target DNA methyltransferase 1 (DNMT1) and hypoxia inducible factor 1 subunit alpha $(\mathrm{HIF} 1 \alpha)$, respectively, which have the potential of promoting cancer cell metastasis and angiogenesis $[159,160]$. Therefore, whereas exosomes secreted by normal fibroblasts might impair cancer progression by downregulating DNMT1 and HIF1 $\alpha$ in cancer cells through delivering miR-148b and miR-320a, the lack of inhibition by CAFs-derived exosomes could boost the cancer progression [142, 143].

The transfer of exosomal proteins from CAFs to cancer cells can also promote tumorigenesis. The breast CAFs derived-exosomes, which contained highly expressed ADAM metallopeptidase domain 10 (ADAM10), promoted cell motility by activating RhoA signaling in breast cancer cells [132]. Meanwhile, ADAM10 plays an important role in the activation of Notch signaling cascade through promoting Site- 2 cleavage of the Notch receptor, followed by $\gamma$-secretase-mediated Site- 3 cleavage to generate Notch intracellular domain and initiate signalling [161]. In oral tongue squamous cell carcinoma (OTSCC), microfibril associated protein 5 (MFAP5) was demonstrated to be enriched in CAFs derived-exosomes. The exosomal transfer of this protein was found to promote OTSCC cell growth and migration by inducing the activation of MAPK and AKT pathways [154]. Also, Sonic Hedgehog $(\mathrm{SHH})$ was detected at highl levels in CAFsderived exosomes. The exosomes mediated transfer of $\mathrm{SHH}$ from CAFs to cancer cells improved proliferation and migration abilities of the esophageal cancer cells in esophageal squamous cell carcinoma (ESCC) [145].

\section{Metabolism}

The CAFs-derived exosomes also have a crucial role in inducing metabolic reprogramming in cancer cells, which is a hallmark of cancer development. The CAFsderived exosomes of prostate cancer, pancreatic cancer and breast cancer have the function in downregulating the mitochondrial function of the cancer cells by inhibiting oxygen consumption rate (OCR) [130, 162]. In prostate cancer, several miRNAs contained in CAFs-derived exosomes were found to have the ability to downregulate mitochondrial oxidative phosphorylation and reprogram metabolic pathways in cancer cells, such as mir-22, let7a and mir-125b [162]. In breast cancer, the CAFs-derived exosomal small nucleolar RNA host gene 3 (SNHG3), which is a lncRNA that acts as a molecular sponge of miR-330-5p to up-regulate pyruvate kinase M1/M2 (PKM) expression, can lead the inhibition of mitochondrial oxidative phosphorylation and enhanced breast tumor cell proliferation [130]. Moreover, the inhibition of mitochondrial oxidative phosphorylation by CAFsderived exosomes is associated with a compensatory increase in glycolysis (i.e., the Warburg effect) [130, 162]. Specially, the exosomes can decrease the percentage conversion of glucose to $\alpha$-ketoglutarate and instead divert it towards lactate in cancer cells.

Furthermore, the CAFs-derived exosomes can increase the level of glutamine for biosynthesis in prostate cancer cells and pancreatic cancer cells by switching the carbon 
source from the oxidative glucose pathway towards glutamine via the reductive carboxylation pathway in the TCA cycle [162]. In addition, the CAFs-derived exosomes also act as a source of metabolite cargos, TCA cycle metabolites, amino acids, and lipids, which can fuel the metabolic activity of the prostate and pancreatic cancer cells [162].

\section{Therapy resistance}

Therapy resistance is a frequent cause of tumor recurrence and treatment failure of cancer patients $[163,164]$. Uptake of CAFs-derived exosomes by cancer cells has been linked to this response.

Tamoxifen is the most commonly used drug for the treatment of ER positive breast cancer [165]. However, many breast cancer patients eventually develop tamoxifen resistance and show a poor prognosis [134]. The tamoxifen resistance in cancer cells can be caused by multiple mechanisms, such as the dysregulation of the ER signaling pathway and PI3K/AKT pathway [166]. Recently, the $\mathrm{CD}^{+}{ }^{+} \mathrm{CAF}$-derived exosomes have been confirmed to perform a crucial role in mediating tamoxifen resistance. The miR-22 is highly expressed in $\mathrm{CD} 63^{+}$ CAF-derived exosomes, which can target estrogen receptor 1 (ESR1) and phosphatase and tensin homolog (PTEN), and suppress the expression of ESR1 and PTEN [134]. The loss of PTEN promotes tamoxifen resistance in breast cancer $[134,167]$.

The CAFs-derived exosomes can also promote the chemotherapy resistance of the cancer cells. Specifically, miR-423-5p transported by the CAFs-derived exosomes can promote resistance to taxane by targeting gremlin 2 (GREM2) and promoting TGF- $\beta$ signaling in prostate cancer. The cancer cells with increased level of miR-423-5p exhibited elevated cell proliferation and the reduced cell apoptosis rate when exposed to taxane [158].

Radiotherapy is being increasingly used as a preoperative treatment owning to its efficiency and effectiveness in lessening the local recurrence of advanced cancer [168]. However, patients often develop resistance to radiotherapy and convert to more aggressive phenotypes, which is partially due to the heterogenous components in TME. In CRC, the CAFs-derived exosomes have been reported as an important cause of radio resistance of cancer cells by preventing the DNA damage and inhibiting apoptosis and in CRC cells. These results were associated with reduced activities of cleaved-caspase 3 and cleavedpoly (ADP-Ribose) polymerase 1 (PARP) induced by CAFs-derived exosomes [139]. The up-regulated miR590-3p in CAFs-derived exosomes compared with normal fibroblast-derived exosomes was confirmed to play a critical role in this regulation by targeting at chloride channel accessory 4 (CLCA4) and activating the PI3K/ AKT signaling pathway [139].

The impact of CAFs-derived exosomes on immune function As discussed in the previous section, CAFs-exosomes can contribute to cancer progression through different mechanisms. Their uptake by cancer cells can (de) activate signaling pathways crucially associated with cell proliferation, migration and invasion [107]. Still, noncancer cell types are also expected to interact with and uptake exosomes secreted at the TME, and the impact of exosomes on these cells may also be critically involved with cancer progression by regulating distinct cancer hallmarks. CAFs have been shown to induce angiogenesis, inflammation and immune suppression, and their impact on the progression of malignant lesions were reviewed by others [23, 37]. Still, the specific contribution of CAFs-exosomes to these process remains largely unexplored. Therefore, this section presents the initial data available in the literature that reports how CAFsderived exosomes can impact immune cells, and discusses it by considering known effects triggered by cancer cell-secreted exosomes mediating immune suppression.

Antitumor immunity is a natural defense against cancer which is in part mediated by immune cells such as $\mathrm{CD}^{+} \mathrm{T}$ cells and NK cells [169]. Specifically, the cytotoxic $\mathrm{CD}^{+} \mathrm{T}$ cells are important for immune-mediated tumor elimination [170, 171]. In order to exert their cytotoxic effect the $\mathrm{T}$ cells needs to complete several steps including $\mathrm{T}$ cell activation, expansion, differentiation and infiltration [34]. This antitumor response can be regulated by multiple cell types, including Treg cells, myeloid cells, endothelial cells, fibroblasts and tumor cells [34].

However, the antitumor response of immune system can meet impediments that contribute to cancer progression. For example, the up-regulated expression of PD-L1 on the surface of cancer cells improve the ability of evading the immune surveillance of cancer cells, which interacts with PD-1 on T cells and mitigate the immune checkpoint response [172]. In melanoma, lung cancer and breast cancer, the cancer cells-derived exosomes have been found to mediate immune suppression via exosomal PD-L1 that inhibit $\mathrm{CD} 8^{+} \mathrm{T}$ cell functions and promote cancer development [173]. The PD-L1 was found to be carried by exosomes on their surface, and this can be up-regulated by interferon- $\gamma$ (IFN- $\gamma$ ). Importantly, the level of PD-L1 in exosomes isolated from plasma of melanoma patients is remarkably higher than that in healthy donors, which positively correlated with metastasis in melanoma patients [173].

Recently, the breast CAFs-derived exosomes have also been found to have inhibitory effect on antitumor immunity. In breast cancer, the PD-L1 expression of cancer cells 
can be up-regulated after the uptake of CAFs-derived exosomes. Specifically, miR-92 was found to be enriched in CAFs-derived exosomes. After being absorbed by cancer cells, the miR-92 targets large tumor suppressor kinase 2 (LATS2) that interacts with Yes-associated protein 1 (YAP1) and regulates nuclear translocation of YAP1 in breast cancer cells. After the nuclear translocation, YAP1 can bind to the enhancer region of PD-L1 and promote transcription activity, which increases the level of PD-L1 in cancer cells [174]. The increased PD-L1 significantly induced apoptosis and impaired proliferation of $\mathrm{T}$ cells and also blocked the cell-killing function of NK cells [174].

\section{The clinical impact of exosomes}

\section{The multicomponent biomarker role in cancer biopsy}

Cancer is a complex and heterogeneous disease that is in a dynamic flux and subject to interplay with host response [175]. Next to histological analysis, detection of cancer biomarkers is an important way to determine the cancer status. Liquid biopsy-based biomarkers for cancer are gaining significance to improve early detection, help diagnosis, predict prognosis and monitor treatment response [26].

The large number of exosomes circulating in body fluids, with unique biogenesis and ubiquitous production by all cell types, are emerging to be a crucial component for biomarker discovery in liquid biopsies. The exosome contents include nucleic acids, lipids, and proteins that can be developed in potential cancer biomarkers. Such biomarkers can inform about the abnormal cancer signaling, the stromal response of tumors, and the physiological status of secretory cells [26]. In addition, there are a considerable proportion of stromal cell-derived exosomes contained in liquid biopsies including CAFs-, immune cells-, mesenchymal cells-, epithelial cells- and endothelial cells-derived exosomes, which could also reflect the host response to cancer pathology.

Recently, a large-scale and comprehensive proteomic analysis of exosomes and exomeres (nonvesicular particles $<50 \mathrm{~nm}$ ) from 426 human samples was performed to identify universal exosome markers to improve the cancer detection $[27,176]$. In this research, the authors defined small exosomes, large exosomes and exomeres collectively as extracellular vesicles and particles (EVPs). Firstly, the proteins composition of EVPs was implicated to be different in various cancer types including pancreatic adenocarcinoma $(\mathrm{PaCa})$ and lung adenocarcinoma (LuCa). In EVPs of $\mathrm{PaCa}$, proteins related with actin cytoskeletal-linked signaling pathways, EMT and coagulation were abundant, while the proteins involved in RNA processing pathways, cell cycle and metabolism were enriched in EVPs of LuCa. Although there are several shared tumor specific EVP proteins that were also enriched in tumor tissues of $\mathrm{PaCa}$ and $\mathrm{LuCa}$, most highly enriched EVP proteins were found to be specific to each respective tumor type. This study demonstrated the heterogeneity of different tumor types at EVPs level. Furthermore, the immunoglobulin-related proteins were enriched in plasma-derived EVPs, which could be an efficient type of biomarkers to distinguish normal and cancer samples. Also, the tumor-associated EVP proteins signature in plasma could be detected before the early stage of metastases. Thus, plasma-circulating EVP proteins could be potential biomarkers for early cancer detection [27].

Notably, the exosomal PD-L1 is a potential maker of immunotherapy treatment response, due to the negative correlation between exosomal PD-L1 levels in plasma of cancer patients and the rate of response to anti-PD-1/ PD-L1 therapy and patients' survival [177-179]. Recently, there is some research indicating that the depletion of exosomal PD-L1 can improve the efficiency of anti-PDL1 blockade in animal models [180, 181]. However, the mechanism of the exosomal PD-L1 in inhibiting the efficiency of anti-PD-1/PD-L1 therapy remains largely unknown. The possible mechanism could be the interaction between circulating exosomal PD-L1 and the anti-PD-1/PD-L1 antibodies, which causes fewer effective antibodies to exert their function in the TME [177]. There are also evidences demonstrated that the elimination of exosomes by inhibiting generation and secretion or extracorporeal hemofiltration may act as an effective add-on therapy to enhance the efficiency of anti-PD-1/ PD-L1 therapy [180, 182, 183], which may provide new clinical application prospects for cancer treatment in future [184].

Up to now exosomes and other EVs have been used as biomarkers for early diagnosis of cancer in many clinical trials. For example, in an ongoing clinical trial, researchers collected blood plasma samples from 420 lung cancer patients and 150 healthy controls to purify the exosomes. Deep-learning analysis of exosomes will be used to screen protein makers to distinguish between healthy controls and lung cancer patients, and then distinguish the early stages of lung cancer patients to improve the survival rates (ClinicalTrials.gov Identifier: NCT04529915). Although there are still challenges using exosomes as a source of biomarkers, exosomes still hold a promising and powerful place in liquid biopsy of cancer [26].

\section{Exosome therapeutics}

Exosomes have a promising prospect of therapeutic applications, as they have the ability of intercellular communication and carrying a variety of cargo 
molecules. Exosomes can serve as delivery vehicles. They can be loaded with therapeutic proteins, therapeutic genes, chemotherapeutic drugs, and small molecules to change the behaviors of target cells [185]. Exosomes can protect the cargos from degradation or neutralization in the body $[185,186]$. The biocompatibility of exosomes, with appropriate modifications, can improve the stability and effectiveness of therapeutics, and enhance the absorption by target cells [187].

As efficient drug carriers, the exosomes have potential to be used for cancer immune therapy. For example, they can enable more efficient anti-cancer vaccines development [187]. Specifically, exosomes can be utilized as the vehicles for carrying protein antagonists in cancer-immune regulation. The CD47 overexpressed on the surface of tumor cells can limit the ability of macrophages to engulf tumor cells by interacting with signal regulatory protein $\alpha(\operatorname{SIRP} \alpha)$ on macrophages; SIRP $\alpha$ acts as a "don't eat me" signal. The exosomes carrying SIRP $\alpha$ variants can antagonize the interaction between CD47 and SIRP $\alpha$ and promote the phagocytosis by macrophages. Also, the SIRP $\alpha$-enriched exosomes can promote the $\mathrm{T}$ cell infiltration in the mouse model, and inhibit the tumor growth ultimately [188]. Furthermore, the native exosomes can be engineered to provide more efficient therapy effects. For example, the pH-responsive exosome nano-bioconjugates composed of M1 macrophages-derived exosomes with antibodies of anti-CD47 and anti-SIRP $\alpha$ through acid-cleavable benzoic-imine bonds has been developed to target the tumor cells. These exosome nano-bioconjugates can release the antibodies after the selective cleavage in the acid tumor microenvironment that block the interaction between SIRP $\alpha$ and CD47, and thereby improve phagocytosis of macrophages [189]. For therapy based on CD47 immune checkpoint blockade, another kind of CD47-overexpressed exosomes fused with drug-loaded thermosensitive liposomes was developed. These hybrid nanovesicles, termed hGLVs, can also improve the macrophages-mediated the phagocytosis of tumor cells by blocking CD47 signal, and induce immunogenic cell death during photothermal therapy [190].

Exosomes have also been used in clinical trials. In a completed clinical trial enrolled 41 participants, dendritic cell-derived exosomes have been used to deliver proteins including melanoma antigen recognized by T cells 1 (MART-1) and MAGE family member A1 (MAGEA1) into NSCLC patients, which can suppress progression of lung cancer by activating the immune response with the induction chemotherapy (ClinicalTrials.gov Identifier: NCT01159288). This strategy of tumor vaccination improved the patient survival in phase II clinical trial [191].
The potential of exosomes as therapeutic tools is a promising and rapidly developing research field, which has great potential to improve the prognosis of patients with metastatic cancer. However, there are still many challenges to be overcome in order to achieve better clinical outcomes.

\section{Concluding remarks}

CAFs are a dominant cell type in the TME, which regulates tumor development in various aspects [35]. The heterogeneity of CAFs lead the tumor to be also more heterogeneous and complex. These characteristics contribute to inefficiency of current cancer chemo-, radio-, targeted-and immune therapies [15]. Not only can CAFs act as a physical barrier to protect the cancer cell from drugs and immune cell, but also the abundant secretion by CAFs can feed the cancer cells continuously and limit the efficiency of chemotherapy and function of immune cells $[15,35,37]$. Here, we mainly discussed the role of CAFs-derived exosomes in cancer development. The CAFs-derived exosomes can serve as transport vehicles carrying different cargos from CAFs to other cells within the TME. These cargos including proteins, nucleic acids, metabolites and other molecules that can fuel cancer cells and promote the proliferation, migration and invasion of cancer cells, induce the metabolic reprogramming of cancer cells and promote the therapy resistance of cancer cells. After the uptake of CAFs-derived exosomes, the cancer cells also gain more abilities to escape from the attack of immune cells. The research regarding the impact of CAF-derived exosomes on cancer cells are rapidly emerging. However, the direct role of CAF-derived exosomes on immune cells remains not well understood. The latter is a very interesting and promising area for future research.

As discussed here, CAF-derived exosomes cargo is commonly altered in comparison with normal fibroblasts-derived exosomes. Alterations in the levels of regulatory molecules (e.g. growth factors and non-coding RNAs) can (de) regulate important signaling pathways in recipient cells, therefore contributing to cancer progression. In addition to altered levels of particular cargo, exosomes secreted by cancer cells have been demonstrated to impact recipient cells by transporting mutated proteins with tumor promoting roles, such as KRAS [192]. Conversely, exosomes were also shown to transport proteins coded by tumor suppressor genes with active function in recipient cells, as exemplified by PTEN [193, 194]. The secretion of exosomes carrying nonmutated proteins can also impact mutated cancer cells by reactivating critical molecular pathways. Still, while this possibility could emerge as promising in terms of cancer progression impairment, a cautious interpretation and 
thorough investigation is otherwise advised before further conclusions. An important example in this matter may involve inactivating mutations in components of the TGF- $\beta$ signaling pathway, which are frequently observed in some types of cancer (e.g., pancreatic and colorectal cancers). While the TGF- $\beta$ signaling pathway is known to suppress tumor initiation and promotion by inhibiting cell proliferation and/or inducing apoptosis in normal or early-stage cancer cells, the activation of TGF- $\beta$ signaling in late-stage tumors promote cancer cell EMT, migration and invasion [34]. Therefore, if non-mutated functional components of the TGF- $\beta$ signaling pathway (e.g. TGF- $\beta$ receptor type II and SMAD4) are indeed transported by CAFs-exosomes to cancer cells, the TGF- $\beta$ signaling pathway could be reactivated, contributing to cancer progression and metastasis in this context [195].

Importantly, exosomes have great potential in clinical applications. The contents in exosomes can serve as selective cancer biomarkers in clinical biopsies, which can reflect the abnormal status of the cells and tissues $[26,28,196]$. The development of biomarkers using exosomes may lead to early cancer (relapse) detection, enable decisions on type of therapy and prevent overtreatment of patients. Also, the exosomes can be used as drug carriers with good biocompatibility, which can be easily absorbed by the target cells with little unexpected immune response [197]. The engineered exosomes with different artificial modifications are also being developed to get more efficient therapeutic effects [185]. Encouragingly, the exosome-loaded cargos acting as tumor vaccines have been used in clinical trials to activate the immune response and inhibit the cancer progression, thus showing promise to improve treatment outcome [191]. Using exosomes as cancer markers or drug carries need further optimization to obtain more stable and efficient effects. In the future, exosomes are likely to play an important role in clinical treatment.

\footnotetext{
Abbreviations

TME:Tumor microenvironment; NK: Natural killer; TAMs: Tumor-associated macrophages TAMs; ECM: Extracellular matrix; ICls: Immune checkpoint inhibitors; CAFs: Cancer associated fibroblasts; EVs: Extracellular vesicles; FAP: Fibroblast activation protein a; a-SMA: a-smooth muscle actin; FSP1: Fibroblastspecific protein 1; PDPN: Podoplanin; PDGFR: Platelet-derived growth factor receptor; myCAFs: myofibroblastic CAFs; FACS: Fluorescence activated cell sorting; ScRNA-seq: Single-cell RNA sequencing; iCAF: Inflammatory CAF; IL-6: Interleukin-6; IL-1 1: Interleukin-11; LIF: Leukemia inhibitory factor; CD25: CD25 antigen; FOXP3: Forkhead box P3; EMT: Epithelial-to-mesenchymal transition; EndMT: Endothelial-to-mesenchymal transition; TGF- $\beta$ : Transforming growth factor- $\beta$; PDAC: Pancreatic ductal adenocarcinoma; Treg cells: Regulatory $T$ cells; ER: Estrogen receptor; Versican: VCAN; IL-1a: interleukin-1 a; IL-33: interleukin-33; SDF1: Stromal cell-derived factor 1; CXCL8: C-X-C motif chemokine ligand 8; COX-2: cyclooxygenase-2; MMPs: Matrix metalloproteinases; VEGF: Vascular endothelial growth factor; WNT2: Wnt family member 2; FGFs: Fibroblast growth factors; CXCL5: C-X-C motif chemokine ligand 5; CXCL12: C-X-C motif chemokine ligand 12; M-CSF: Macrophage colony-stimulating factor;
}

PD-1: Programmed cell death 1; PD-2: Programmed cell death 2; PGE2: Prostaglandin E2; Cav-1: caveolin-1; CCL5: C-C motif chemokine ligand 5; CXCL10: C-X-C motif chemokine ligand 10; SATB-1: Special AT-rich sequence-binding protein-1; GJIC: Gap junctional intercellular communication; NSCLC: Nonsmall cell lung cancer; Cx43: connexin 43; TCA: Tricarboxylic acid; PI3K/AKT: Phosphatidylinositol 3-kinase/protein kinase B; MAPK/ERK: mitogen-activated protein kinases/extracellular signal-regulated kinase; HAPLN1: Hyaluronan and proteoglycan link protein 1; NEAA: Non-essential amino acids; MISEV2018: Minimal information for studies of extracellular vesicles 2018; ISEV: International Society for Extracellular Vesicles; sEVs: small EVs; m/IEVs: medium/large EVs; MVBs: multi-vesicular bodies; ILVs: Intraluminal vesicles; ESCRT: Endosomal sorting complex required for transport; ALIX: Apoptosis-linked gene 2-interacting protein $X_{;}$VTA1: Vesicle trafficking 1; SNARE: Soluble N-ethylmaleimidesensitive factor attachment protein receptor; MiRNAs: microRNAs; CDX2:

Caudal-related homeobox 2; HOXA5: Homeobox A5; USP28: Ubiquitin-specific peptidase 28; CircRNAs: circular RNAs; CD44: CD44 molecule; CRC: Colorectal cancer; LncRNAs: long noncoding RNAs; ANXA2: Annexin A2; DNMT1: DNA methyltransferase 1; HIF1a: hypoxia inducible factor 1 subunit alpha; ADAM10: ADAM metallopeptidase domain 10; OTSCC: Oral tongue squamous cell carcinoma; MFAP5: microfibril associated protein 5; SHH: Sonic Hedgehog; ESCC: Esophageal squamous cell carcinoma; OCR: Oxygen consumption rate; SNHG3: Small nucleolar RNA host gene 3; PKM: Pyruvate kinase M1/M2; ESR1: Estrogen receptor 1; PTEN: Phosphatase and tensin homolog; GREM2: gremlin 2; PARP: Poly (ADP-Ribose) polymerase 1; CLCA4: Chloride channel accessory 4 CXCR5: C-X-C motif chemokine receptor 5; PD-L1: Programmed death-ligand 1; ALOX15: Arachidonate lipoxygenase 15; JAK1/STAT1: janus kinase 1/ signal transducer And activator of transcription 1; BCL2: BCL2 apoptosis regulator; PBX3: PBX homeobox 3; AXL: AXL receptor tyrosine kinase; SCAI: Suppressor of cancer cell invasion; CDKN1A: cyclin dependent kinase inhibitor 1A; FOSL1: FOS like antigen 1; IFN- $\gamma$ : interferon- $\gamma$; LATS2: Large tumor suppressor kinase 2; YAP1: Yes-associated protein 1; EVPs: Extracellular vesicles and particles; PaCa: Pancreatic adenocarcinoma; LuCa: Lung adenocarcinoma; SIRPa: signal regulatory protein a; MART-1: melanoma antigen recognized by T cells 1; MAGEA1: MAGE family member A1.

\section{Acknowledgements}

We thank Marten Hornsveld and Yuanzhuo Gu for their precious advice, and other colleagues for stimulating discussions.

\section{Authors' contributions}

$\mathrm{CL}$ drafted the manuscript. PTD designed the study and revised the manuscript. HJZ and AFT discussed and revised the manuscript. All authors read and approved the final manuscript.

\section{Funding}

This work was supported by Cancer Genomics Centre Netherlands (CGC.NL to $\mathrm{PtD}$ ) and Chinese Scholarship Council (to CL).

Availability of data and materials

Not applicable.

\section{Declarations}

Ethics approval and consent to participate

Not applicable.

Consent for publication

Not applicable.

\section{Competing interests}

The authors declare that they have no competing interests.

\section{Author details}

${ }^{1}$ Oncode Institute and Department of Cell and Chemical Biology, Leiden University Medical Center, Leiden, Netherlands. ${ }^{2}$ Department of Surgery, The Royal Melbourne Hospital, The University of Melbourne, Parkville, VIC, Australia.

Received: 1 October 2021 Accepted: 11 November 2021

Published online: 01 December 2021 


\section{References}

1. Hanahan D, Weinberg RA. Hallmarks of cancer: the next generation. Cell. 2011;144(5):646-74.

2. Herschman HR. Primary response genes induced by growth factors and tumor promoters. Annu Rev Biochem. 1991;60:281-319.

3. Dvorak HF. Tumors: Wounds That Do Not Heal-A Historical Perspective with a Focus on the Fundamental Roles of Increased Vascular Permeability and Clotting. Semin Thromb Hemost. 2019;45(6):576-92.

4. Dvorak HF. Tumors: wounds that do not heal. Similarities between tumor stroma generation and wound healing. N Engl J Med. 1986;315(26):1650-9.

5. Sundaram GM, Quah S, Sampath P. Cancer: the dark side of wound healing. FEBS J. 2018;285(24):4516-34.

6. Ribeiro Franco PI, Rodrigues AP, de Menezes LB, Pacheco MM. Tumor microenvironment components: Allies of cancer progression. Pathol Res Pract. 2020:216(1):152729.

7. Wu T, Dai Y. Tumor microenvironment and therapeutic response. Cancer Lett. 2017:387:61-8.

8. Roma-Rodrigues C, Mendes R, Baptista PV, Fernandes AR. Targeting Tumor Microenvironment for Cancer Therapy. Int J Mol Sci. 2019;20(4):840.

9. Denton AE, Roberts EW, Fearon DT. Stromal Cells in the Tumor Microenvironment. Adv Exp Med Biol. 2018;1060:99-114

10. Blomberg OS, Spagnuolo L, de Visser KE. Immune regulation of metastasis: mechanistic insights and therapeutic opportunities. Dis Model Mech. 2018;11(10):dmm036236.

11. Sharma P, Allison JP. Dissecting the mechanisms of immune checkpoint therapy. Nat Rev Immunol. 2020;20(2):75-6.

12. Song Y, Fu Y, Xie Q, Zhu B, Wang J, Zhang B. Anti-angiogenic Agents in Combination With Immune Checkpoint Inhibitors: A Promising Strategy for Cancer Treatment. Front Immunol. 2020;11:1956.

13. Olejarz W, Kubiak-Tomaszewska G, Chrzanowska A, Lorenc T. Exosomes in Angiogenesis and Anti-angiogenic Therapy in Cancers. Int J Mol Sci. 2020;21(16):5840.

14. Lee WS, Yang H, Chon HJ, Kim C. Combination of anti-angiogenic therapy and immune checkpoint blockade normalizes vascularimmune crosstalk to potentiate cancer immunity. Exp Mol Med. 2020;52(9):1475-85.

15. LeBleu VS, Kalluri R. A peek into cancer-associated fibroblasts: origins, functions and translational impact. Dis Model Mech. 2018;11(4):dmm029447.

16. Ziani L, Chouaib S, Thiery J. Alteration of the Antitumor Immune Response by Cancer-Associated Fibroblasts. Front Immunol. 2018;9:414.

17. Ohlund D, Elyada E, Tuveson D. Fibroblast heterogeneity in the cancer wound. J Exp Med. 2014;211(8):1503-23.

18. Erkan M, Hausmann S, Michalski CW, Fingerle AA, Dobritz M, Kleeff J, et al. The role of stroma in pancreatic cancer: diagnostic and therapeutic implications. Nat Rev Gastroenterol Hepatol. 2012;9(8):454-67.

19. Kanzaki R, Pietras K. Heterogeneity of cancer-associated fibroblasts: Opportunities for precision medicine. Cancer Sci. 2020;111(8):2708-17.

20. Miyai Y, Esaki N, Takahashi M, Enomoto A. Cancer-associated fibroblasts that restrain cancer progression: Hypotheses and perspectives. Cancer Sci. 2020;111(4):1047-57.

21. Chandra Jena B, Sarkar S, Rout L, Mandal M. The transformation of cancer-associated fibroblasts: Current perspectives on the role of TGFbeta in CAF mediated tumor progression and therapeutic resistance. Cancer Lett. 2021;520:222-32.

22. Biffi G, Tuveson DA. Diversity and Biology of Cancer-Associated Fibroblasts. Physiol Rev. 2021;101(1):147-76.

23. Bu L, Baba H, Yoshida N, Miyake K, Yasuda T, Uchihara T, et al. Biological heterogeneity and versatility of cancer-associated fibroblasts in the tumor microenvironment. Oncogene. 2019;38(25):4887-901.

24. Kobayashi H, Enomoto A, Woods SL, Burt AD, Takahashi M, Worthley DL. Cancer-associated fibroblasts in gastrointestinal cancer. Nat Rev Gastroenterol Hepatol. 2019;16(5):282-95.

25. Nurmik M, Ullmann P, Rodriguez F, Haan S, Letellier E. In search of definitions: Cancer-associated fibroblasts and their markers. Int J Cancer. 2020;146(4):895-905.

26. LeBleu VS, Kalluri R. Exosomes as a Multicomponent Biomarker Platform in Cancer. Trends Cancer. 2020;6(9):767-74
27. Hoshino A, Kim HS, Bojmar L, Gyan KE, Cioffi M, Hernandez J, et al. Extracellular Vesicle and Particle Biomarkers Define Multiple Human Cancers. Cell. 2020;182(4):1044-61.

28. Gurunathan S, Kang MH, Jeyaraj M, Qasim M, Kim JH. Review of the Isolation, Characterization, Biological Function, and Multifarious Therapeutic Approaches of Exosomes. Cells. 2019;8(4):307.

29. Seo N, Akiyoshi K, Shiku H. Exosome-mediated regulation of tumor immunology. Cancer Sci. 2018;109(10):2998-3004.

30. Knox MC, Ni J, Bece A, Bucci J, Chin Y, Graham PH, et al. A Clinician's Guide to Cancer-Derived Exosomes: Immune Interactions and Therapeutic Implications. Front Immunol. 2020;11:1612.

31. Yan W, Jiang S. Immune Cell-Derived Exosomes in the Cancer-Immunity Cycle. Trends Cancer. 2020;6(6):506-17.

32. Huang Y, Liu K, Li Q, Yao Y, Wang Y. Exosomes Function in Tumor Immune Microenvironment. Adv Exp Med Biol. 2018;1056:109-22.

33. Graner MW, Schnell S, Olin MR. Tumor-derived exosomes, microRNAs, and cancer immune suppression. Semin Immunopathol. 2018:40(5):505-15.

34. Derynck R, Turley SJ, Akhurst RJ. TGF $\beta$ biology in cancer progression and immunotherapy. Nat Rev Clin Oncol. 2020;18(1):9-34.

35. Sahai E, Astsaturov I, Cukierman E, DeNardo DG, Egeblad M, Evans RM, et al. A framework for advancing our understanding of cancer-associated fibroblasts. Nat Rev Cancer. 2020;20(3):174-86.

36. Barrett R, Pure E. Cancer-associated fibroblasts: key determinants of tumor immunity and immunotherapy. Curr Opin Immunol. 2020;64:80-7.

37. Fiori ME, Di Franco S, Villanova L, Bianca P, Stassi G, De Maria R. Cancer-associated fibroblasts as abettors of tumor progression at the crossroads of EMT and therapy resistance. Mol Cancer. 2019;18(1):70.

38. Ehrlich HP, Allison GM, Leggett M. The myofibroblast, cadherin, alpha smooth muscle actin and the collagen effect. Cell Biochem Funct. 2006:24(1):63-70.

39. Mizutani Y, Kobayashi H, lida T, Asai N, Masamune A, Hara A, et al. Meflin-Positive Cancer-Associated Fibroblasts Inhibit Pancreatic Carcinogenesis. Cancer Res. 2019;79(20):5367-81.

40. Park D, Sahai E, Rullan A. SnapShot: Cancer-Associated Fibroblasts. Cell. 2020;181(2):486.

41. Ohlund D, Handly-Santana A, Biffi G, Elyada E, Almeida AS, Ponz-Sarvise $M$, et al. Distinct populations of inflammatory fibroblasts and myofibroblasts in pancreatic cancer. J Exp Med. 2017;214(3):579-96.

42. Elyada E, Bolisetty M, Laise P, Flynn WF, Courtois ET, Burkhart RA, et al. Cross-Species Single-Cell Analysis of Pancreatic Ductal Adenocarcinoma Reveals Antigen-Presenting Cancer-Associated Fibroblasts. Cancer Discov. 2019;9(8):1102-23.

43. Costa A, Kieffer Y, Scholer-Dahirel A, Pelon F, Bourachot B, Cardon M et al. Fibroblast Heterogeneity and Immunosuppressive Environment in Human Breast Cancer. Cancer Cell. 2018:33(3):463-79.

44. Li H, Courtois ET, Sengupta D, Tan Y, Chen KH, Goh JJL, et al. Reference component analysis of single-cell transcriptomes elucidates cellular heterogeneity in human colorectal tumors. Nat Genet. 2017;49(5):708-18.

45. Hosaka K, Yang Y, Seki T, Fischer C, Dubey O, Fredlund E, et al. Pericytefibroblast transition promotes tumor growth and metastasis. Proc Natl Acad Sci U S A. 2016;113(38):E5618-27.

46. Kieffer Y, Hocine HR, Gentric G, Pelon F, Bernard C, Bourachot B, et al. Single-Cell Analysis Reveals Fibroblast Clusters Linked to Immunotherapy Resistance in Cancer. Cancer Discov. 2020;10(9):1330-51.

47. Bartoschek M, Oskolkov N, Bocci M, Lovrot J, Larsson C, Sommarin M, et al. Spatially and functionally distinct subclasses of breast cancerassociated fibroblasts revealed by single cell RNA sequencing. Nat Commun. 2018;9(1):5150.

48. Dominguez CX, Muller S, Keerthivasan S, Koeppen H, Hung J, Gierke $S$, et al. Single-Cell RNA Sequencing Reveals Stromal Evolution into LRRC15(+) Myofibroblasts as a Determinant of Patient Response to Cancer Immunotherapy. Cancer Discov. 2020;10(2):232-53.

49. Ji T, Zhao Y, Ding Y, Wang J, Zhao R, Lang J, et al. Transformable Peptide Nanocarriers for Expeditious Drug Release and Effective Cancer Therapy via Cancer-Associated Fibroblast Activation. Angew Chem Int Ed Engl. 2016;55(3):1050-5.

50. Flaberg E, Markasz L, Petranyi G, Stuber G, Dicso F, Alchihabi N, et al. High-throughput live-cell imaging reveals differential inhibition of tumor cell proliferation by human fibroblasts. Int J Cancer. 2011:128(12):2793-802. 
51. Engle SJ, Hoying JB, Boivin GP, Ormsby I, Gartside PS, Doetschman T. Transforming growth factor $\beta 1$ suppresses nonmetastatic colon cancer at an early stage of tumorigenesis. Cancer Res. 1999;59(14):3379-86.

52. Ozdemir BC, Pentcheva-Hoang T, Carstens JL, Zheng X, Wu CC, Simpson $T R$, et al. Depletion of carcinoma-associated fibroblasts and fibrosis induces immunosuppression and accelerates pancreas cancer with reduced survival. Cancer Cell. 2014;25(6):719-34.

53. Brechbuhl HM, Finlay-Schultz J, Yamamoto TM, Gillen AE, Cittelly DM, Tan AC, et al. Fibroblast Subtypes Regulate Responsiveness of Luminal Breast Cancer to Estrogen. Clin Cancer Res. 2017;23(7):1710-21.

54. Fanhchaksai K, Okada F, Nagai N, Pothacharoen P, Kongtawelert $P$, Hatano $S$, et al. Host stromal versican is essential for cancerassociated fibroblast function to inhibit cancer growth. Int J Cancer. 2016;138(3):630-41.

55. Chen X, Song E. Turning foes to friends: targeting cancer-associated fibroblasts. Nat Rev Drug Discov. 2019;18(2):99-115.

56. Barbazan J, Matic VD. Cancer associated fibroblasts: is the force the path to the dark side? Curr Opin Cell Biol. 2019;56:71-9.

57. Wei L, Ye H, Li G, Lu Y, Zhou Q, Zheng S, et al. Cancer-associated fibroblasts promote progression and gemcitabine resistance via the SDF-1/ SATB-1 pathway in pancreatic cancer. Cell Death Dis. 2018;9(11):1065.

58. Qin X, Yan M, Wang X, Xu Q, Wang X, Zhu X, et al. Cancer-associated Fibroblast-derived IL-6 Promotes Head and Neck Cancer Progression via the Osteopontin-NF-kappa B Signaling Pathway. Theranostics. 2018:8(4):921-40.

59. Landskron G, De la Fuente LM, Dubois-Camacho K, Diaz-Jimenez D, Orellana-Serradell O, Romero D, et al. Interleukin 33/ST2 Axis Components Are Associated to Desmoplasia, a Metastasis-Related Factor in Colorectal Cancer. Front Immunol. 2019:10:1394.

60. Ligorio M, Sil S, Malagon-Lopez J, Nieman LT, Misale S, Di Pilato M, et al. Stromal Microenvironment Shapes the Intratumoral Architecture of Pancreatic Cancer. Cell. 2019;178(1):160-75.

61. Kale S, Raja R, Thorat D, Soundararajan G, Patil TV, Kundu GC. Osteopontin signaling upregulates cyclooxygenase-2 expression in tumor-associated macrophages leading to enhanced angiogenesis and melanoma growth via alpha9beta1 integrin. Oncogene. 2015;34(42):5408-10.

62. Ren $Y$, Jia HH, Xu YQ, Zhou X, Zhao XH, Wang YF, et al. Paracrine and epigenetic control of CAF-induced metastasis: the role of HOTAIR stimulated by TGF-ss1 secretion. Mol Cancer. 2018;17(1):5.

63. Yu Y, Xiao CH, Tan LD, Wang QS, Li XQ, Feng YM. Cancer-associated fibroblasts induce epithelial-mesenchymal transition of breast cancer cells through paracrine TGF-beta signalling. Br J Cancer. 2014;110(3):724-32.

64. Paauwe M, Schoonderwoerd MJA, Helderman R, Harryvan TJ, Groenewoud A, van Pelt GW, et al. Endoglin Expression on Cancer-Associated Fibroblasts Regulates Invasion and Stimulates Colorectal Cancer Metastasis. Clin Cancer Res. 2018:24(24):6331-44.

65. Tan HX, Gong WZ, Zhou K, Xiao ZG, Hou FT, Huang T, et al. CXCR4/TGFbeta1 mediated hepatic stellate cells differentiation into carcinomaassociated fibroblasts and promoted liver metastasis of colon cancer. Cancer Biol Ther. 2020;21(3):258-68.

66. Lugano R, Ramachandran M, Dimberg A. Tumor angiogenesis: causes, consequences, challenges and opportunities. Cell Mol Life Sci. 2020;77(9):1745-70.

67. Kubo N, Araki K, Kuwano H, Shirabe K. Cancer-associated fibroblasts in hepatocellular carcinoma. World J Gastroenterol. 2016;22(30):6841-50.

68. Kugeratski FG, Atkinson SJ, Neilson L, Lilla S, Knight JRP, Serneels J, et al. Hypoxic cancer-associated fibroblasts increase NCBP2-AS2/HIAR to promote endothelial sprouting through enhanced VEGF signaling. Sci Signal. 2019;12(567):eaan8247.

69. Unterleuthner D, Neuhold P, Schwarz K, Janker L, Neuditschko B, Nivarthi $\mathrm{H}$, et al. Cancer-associated fibroblast-derived WNT2 increases tumor angiogenesis in colon cancer. Angiogenesis. 2020;23(2):159-77.

70. Sun $Q$, Zhang B, Hu Q, Qin Y, Xu W, Liu W, et al. The impact of cancerassociated fibroblasts on major hallmarks of pancreatic cancer. Theranostics. 2018;8(18):5072-87.

71. Petty AJ, Yang Y. Tumor-associated macrophages: implications in cancer immunotherapy. Immunotherapy. 2017;9(3):289-302.

72. Berzaghi R, Ahktar MA, Islam A, Pedersen BD, Hellevik T, MartinezZubiaurre I. Fibroblast-Mediated Immunoregulation of Macrophage Function Is Maintained after Irradiation. Cancers (Basel). 2019;1 (5):689.
73. Zhang A, Qian Y, Ye Z, Chen H, Xie H, Zhou L, et al. Cancer-associated fibroblasts promote $\mathrm{M} 2$ polarization of macrophages in pancreatic ductal adenocarcinoma. Cancer Med. 2017;6(2):463-70.

74. Comito G, Giannoni E, Segura CP, Barcellos-de-Souza P, Raspollini MR, Baroni G, et al. Cancer-associated fibroblasts and M2-polarized macrophages synergize during prostate carcinoma progression. Oncogene. 2014;33(19):2423-31.

75. Pinchuk IV, Saada JI, Beswick EJ, Boya G, Qiu SM, Mifflin RC, et al. PD-1 ligand expression by human colonic myofibroblasts/fibroblasts regulates CD4+ T-cell activity. Gastroenterology. 2008;135(4):1228-37.

76. Li T, Yang Y, Hua X, Wang G, Liu W, Jia C, et al. Hepatocellular carcinomaassociated fibroblasts trigger NK cell dysfunction via PGE2 and IDO. Cancer Lett. 2012;318(2):154-61.

77. Schwartz L, Supuran CT, Alfarouk KO. The Warburg Effect and the Hallmarks of Cancer. Anti Cancer Agents Med Chem. 2017;17(2):164-70.

78. Vaupel $\mathrm{P}$, Schmidberger $\mathrm{H}$, Mayer A. The Warburg effect: essential part of metabolic reprogramming and central contributor to cancer progression. Int J Radiat Biol. 2019;95(7):912-9.

79. Pavlides S, Whitaker-Menezes D, Castello-Cros R, Flomenberg N, Witkiewicz AK, Frank PG, et al. The reverse Warburg effect: aerobic glycolysis in cancer associated fibroblasts and the tumor stroma. Cell Cycle. 2009;8(23):3984-4001.

80. Gentric G, Mechta-Grigoriou F. Tumor Cells and Cancer-Associated Fibroblasts: An Updated Metabolic Perspective. Cancers (Basel). 2021;13(3):399.

81. Wilde L, Roche M, Domingo-Vidal M, Tanson K, Philp N, Curry J, et al. Metabolic coupling and the Reverse Warburg Effect in cancer: Implications for novel biomarker and anticancer agent development. Semin Oncol. 2017:44(3):198-203.

82. Shen XJ, Zhang H, Tang GS, Wang XD, Zheng R, Wang Y, et al. Caveolin-1 is a modulator of fibroblast activation and a potential biomarker for gastric cancer. Int J Biol Sci. 2015;11(4):370-9.

83. Simpkins SA, Hanby AM, Holliday DL, Speirs V. Clinical and functional significance of loss of caveolin-1 expression in breast cancer-associated fibroblasts. J Pathol. 2012;227(4):490-8.

84. Olivares $\mathrm{O}$, Mayers JR, Gouirand V, Torrence ME, Gicquel T, Borge L, et al. Collagen-derived proline promotes pancreatic ductal adenocarcinoma cell survival under nutrient limited conditions. Nat Commun. 2017:8:16031

85. Curtis M, Kenny HA, Ashcroft B, Mukherjee A, Johnson A, Zhang Y, et al. Fibroblasts Mobilize Tumor Cell Glycogen to Promote Proliferation and Metastasis. Cell Metab. 2019;29(1):141-55.

86. Sanford-Crane H, Abrego J, Sherman MH. Fibroblasts as Modulators of Local and Systemic Cancer Metabolism. Cancers (Basel). 2019;11(5):619.

87. Dominiak A, Chelstowska B, Olejarz W, Nowicka G. Communication in the Cancer Microenvironment as a Target for Therapeutic Interventions. Cancers (Basel). 2020;12(5):1232.

88. Pellman J, Zhang J, Sheikh F. Myocyte-fibroblast communication in cardiac fibrosis and arrhythmias: Mechanisms and model systems. J Mol Cell Cardiol. 2016;94:22-31.

89. Roehlecke C, Schmidt MHH. Tunneling Nanotubes and Tumor Microtubes in Cancer. Cancers (Basel). 2020;12(4):857.

90. Maeda S, Nakagawa S, Suga M, Yamashita E, Oshima A, Fujiyoshi Y, et al. Structure of the connexin 26 gap junction channel at 3.5 A resolution. Nature. 2009;458(7238):597-602.

91. Qu Y, Dahl G. Function of the voltage gate of gap junction channels: selective exclusion of molecules. Proc Natl Acad Sci U S A. 2002:99(2):697-702.

92. Luo M, Luo Y, Mao N, Huang G, Teng C, Wang H, et al. Cancer-Associated Fibroblasts Accelerate Malignant Progression of Non-Small Cell Lung Cancer via Connexin 43-Formed Unidirectional Gap Junctional Intercellular Communication. Cell Physiol Biochem. 2018;51(1):315-36.

93. Trautmann A, Feuerstein B, Ernst N, Brocker EB, Klein CE. Heterotypic cell-cell adhesion of human mast cells to fibroblasts. Arch Dermatol Res. 1997;289(4):194-203.

94. Adachi S, Ebi Y, Nishikawa S, Hayashi S, Yamazaki M, Kasugai T, et al. Necessity of extracellular domain of W (c-kit) receptors for attachment of murine cultured mast cells to fibroblasts. Blood. 1992;79(3):650-6.

95. Trautmann A, Krohne G, Bröcker EB, Klein CE. Human mast cells augment fibroblast proliferation by heterotypic cell-cell adhesion and action of IL-4. J Immunol. 1998;160(10):5053-7. 
96. Wright DB, Meurs H, Dekkers BG. Integrins: therapeutic targets in airway hyperresponsiveness and remodelling? Trends Pharmacol Sci. 2014;35(11):567-74

97. Valiente-Alandi I, Schafer AE, Blaxall BC. Extracellular matrix-mediated cellular communication in the heart. J Mol Cell Cardiol. 2016;91:228-37.

98. Simian M, Hirai Y, Navre M, Werb Z, Lochter A, Bissell MJ. The interplay of matrix metalloproteinases, morphogens and growth factors is necessary for branching of mammary epithelial cells. Development. 2001;128(16):3117-31.

99. Santi A, Kugeratski FG, Zanivan S. Cancer Associated Fibroblasts: The Architects of Stroma Remodeling. Proteomics. 2018;18(5-6):e1700167.

100. Lee HO, Mullins SR, Franco-Barraza J, Valianou M, Cukierman E, Cheng JD. FAP-overexpressing fibroblasts produce an extracellular matrix that enhances invasive velocity and directionality of pancreatic cancer cells. BMC Cancer. 2011;11:245.

101. Kaur A, Ecker BL, Douglass SM, Kugel CH 3rd, Webster MR, Almeida FV, et al. Remodeling of the Collagen Matrix in Aging Skin Promotes Melanoma Metastasis and Affects Immune Cell Motility. Cancer Discov. 2019;9(1):64-81

102. Monteran L, Erez N. The Dark Side of Fibroblasts: Cancer-Associated Fibroblasts as Mediators of Immunosuppression in the Tumor Microenvironment. Front Immunol. 2019;10:1835.

103. Bertero T, Oldham WM, Grasset EM, Bourget I, Boulter E, Pisano S, et al. Tumor-Stroma Mechanics Coordinate Amino Acid Availability to Sustain Tumor Growth and Malignancy. Cell Metab. 2019;29(1):124-40.

104. Valencia T, Kim JY, Abu-Baker S, Moscat-Pardos J, Ahn CS, Reina-Campos $M$, et al. Metabolic reprogramming of stromal fibroblasts through p62mTORC1 signaling promotes inflammation and tumorigenesis. Cancer Cell. 2014;26(1):121-35.

105. Sousa CM, Biancur DE, Wang X, Halbrook CJ, Sherman MH, Zhang L, et al. Pancreatic stellate cells support tumour metabolism through autophagic alanine secretion. Nature. 2016;536(7617):479-83.

106. Thery C, Witwer KW, Aikawa E, Alcaraz MJ, Anderson JD, Andriantsitohaina $\mathrm{R}$, et al. Minimal information for studies of extracellular vesicles 2018 (MISEV2018): a position statement of the International Society for Extracellular Vesicles and update of the MISEV2014 guidelines. J Extracell Vesicles. 2018;7(1):1535750.

107. Bian X, Xiao YT, Wu T, Yao M, Du L, Ren S, et al. Microvesicles and chemokines in tumor microenvironment: mediators of intercellular communications in tumor progression. Mol Cancer. 2019;18(1):50.

108. Szatanek R, Baj-Krzyworzeka M, Zimoch J, Lekka M, Siedlar M, Baran J. The Methods of Choice for Extracellular Vesicles (EVs) Characterization. Int J Mol Sci. 2017;18(6):1153.

109. Menck K, Sivaloganathan S, Bleckmann A, Binder C. Microvesicles in Cancer: Small Size, Large Potential. Int J Mol Sci. 2020;21(15):5373.

110. Yang X, Li Y, Zou L, Zhu Z. Role of Exosomes in Crosstalk Between Cancer-Associated Fibroblasts and Cancer Cells. Front Oncol. 2019;9:356.

111. Dai J, Su Y, Zhong S, Cong L, Liu B, Yang J, et al. Exosomes: key players in cancer and potential therapeutic strategy. Signal Transduct Target Ther. 2020;5(1):145

112. Bebelman MP, Smit MJ, Pegtel DM, Baglio SR. Biogenesis and function of extracellular vesicles in cancer. Pharmacol Ther. 2018;188:1-11.

113. Kalluri R, LeBleu VS. The biology, function, and biomedical applications of exosomes. Science. 2020;367(6478):eaau6977.

114. Hessvik NP, Llorente A. Current knowledge on exosome biogenesis and release. Cell Mol Life Sci. 2018;75(2):193-208.

115. Mashouri L, Yousefi H, Aref AR, Ahadi AM, Molaei F, Alahari SK. Exosomes: composition, biogenesis, and mechanisms in cancer metastasis and drug resistance. Mol Cancer. 2019;18(1):75.

116. Roucourt B, Meeussen S, Bao J, Zimmermann P, David G. Heparanase activates the syndecan-syntenin-ALIX exosome pathway. Cell Res. 2015;25(4):412-28.

117. Staubach S, Wenzel A, Beck BB, Rinschen MM, Muller S, Hanisch FG. Autosomal Tubulointerstitial Kidney Disease-MUC1 Type: Differential Proteomics Suggests that Mutated MUC1 (insC) Affects Vesicular Transport in Renal Epithelial Cells. Proteomics. 2018;18(7):e1700456.

118. Yu Z, Shi M, Stewart T, Fernagut PO, Huang Y, Tian C, et al. Reduced oligodendrocyte exosome secretion in multiple system atrophy involves SNARE dysfunction. Brain. 2020;143(6):1780-97.
119. Ostrowski M, Carmo NB, Krumeich S, Fanget I, Raposo G, Savina A, et al. Rab27a and Rab27b control different steps of the exosome secretion pathway. Nat Cell Biol. 2010;12(1):19-30.

120. Abels ER, Breakefield XO. Introduction to Extracellular Vesicles: Biogenesis, RNA Cargo Selection, Content, Release, and Uptake. Cell Mol Neurobiol. 2016;36(3):301-12.

121. Gonda A, Kabagwira J, Senthil GN, Wall NR. Internalization of Exosomes through Receptor-Mediated Endocytosis. Mol Cancer Res. 2019;17(2):337-47.

122. Tian T, Zhu YL, Zhou YY, Liang GF, Wang YY, Hu FH, et al. Exosome uptake through clathrin-mediated endocytosis and macropinocytosis and mediating miR-21 delivery. J Biol Chem. 2014;289(32):22258-67.

123. Buratta S, Tancini B, Sagini K, Delo F, Chiaradia E, Urbanelli L, et al. Lysosomal Exocytosis, Exosome Release and Secretory Autophagy: The Autophagic- and Endo-Lysosomal Systems Go Extracellular. Int J Mol Sci. 2020;21(7):2576

124. van Niel G, D'Angelo G, Raposo G. Shedding light on the cell biology of extracellular vesicles. Nat Rev Mol Cell Biol. 2018:19(4):213-28.

125. Pegtel DM, Gould SJ. Exosomes. Annu Rev Biochem. 2019;88:487-514

126. Li W, Li C, Zhou T, Liu X, Liu X, Li X, et al. Role of exosomal proteins in cancer diagnosis. Mol Cancer. 2017;16(1):145.

127. von Ahrens D, Bhagat TD, Nagrath D, Maitra A, Verma A. The role of stromal cancer-associated fibroblasts in pancreatic cancer. J Hematol Oncol. 2017;10(1):76.

128. Shan G, Zhou X, Gu J, Zhou D, Cheng W, Wu H, et al. Downregulated exosomal microRNA-148b-3p in cancer associated fibroblasts enhance chemosensitivity of bladder cancer cells by downregulating the Wnt/ beta-catenin pathway and upregulating PTEN. Cell Oncol (Dordr) 2021:44(1):45-59.

129. Wang H, Wei H, Wang J, Li L, Chen A, Li Z. MicroRNA-181d-5p-Containing Exosomes Derived from CAFs Promote EMT by Regulating CDX2/ HOXA5 in Breast Cancer. Mol Ther Nucleic Acids. 2020;19:654-67.

130. Li Y, Zhao Z, Liu W, Li X. SNHG3 Functions as miRNA Sponge to Promote Breast Cancer Cells Growth Through the Metabolic Reprogramming. Appl Biochem Biotechnol. 2020;191(3):1084-99.

131. Donnarumma E, Fiore D, Nappa M, Roscigno G, Adamo A, laboni $\mathrm{M}$, et al. Cancer-associated fibroblasts release exosomal microRNAs that dictate an aggressive phenotype in breast cancer. Oncotarget. 2017;8(12):19592-608.

132. Shimoda M, Principe $S$, Jackson HW, Luga V, Fang H, Molyneux SD, et al. Loss of the Timp gene family is sufficient for the acquisition of the CAFlike cell state. Nat Cell Biol. 2014;16(9):889-901.

133. Chen B, Sang Y, Song X, Zhang D, Wang L, Zhao W, et al. Exosomal miR500a-5 $p$ derived from cancer-associated fibroblasts promotes breast cancer cell proliferation and metastasis through targeting USP28. Theranostics. 2021;11(8):3932-47.

134. Gao Y, Li X, Zeng C, Liu C, Hao Q, Li W, et al. CD63(+) Cancer-Associated Fibroblasts Confer Tamoxifen Resistance to Breast Cancer Cells through Exosomal miR-22. Adv Sci (Weinh). 2020;7(21):2002518.

135. Zhan Y, Du J, Min Z, Ma L, Zhang W, Zhu W, et al. Carcinoma-associated fibroblasts derived exosomes modulate breast cancer cell stemness through exonic circHIF1A by miR-580-5p in hypoxic stress. Cell Death Discov. 2021;7(1):141.

136. Kim JE, Kim BG, Jang Y, Kang S, Lee JH, Cho NH. The stromal loss of miR4516 promotes the FOSL1-dependent proliferation and malignancy of triple negative breast cancer. Cancer Lett. 2020;469:256-65.

137. Ren J, Ding L, Zhang D, Shi G, Xu Q, Shen S, et al. Carcinoma-associated fibroblasts promote the stemness and chemoresistance of colorectal cancer by transferring exosomal IncRNA H19. Theranostics. 2018:8(14):3932-48.

138. Zhou L, Li J, Tang Y, Yang M. Exosomal LncRNA LINC00659 transferred from cancer-associated fibroblasts promotes colorectal cancer cell progression via miR-342-3p/ANXA2 axis. J Transl Med. 2021;19(1):8.

139. Chen X, Liu Y, Zhang Q, Liu B, Cheng Y, Zhang Y, et al. Exosomal miR590-3p derived from cancer-associated fibroblasts confers radioresistance in colorectal cancer. Mol Ther Nucleic Acids. 2021;24:113-26.

140. Gu C, Lu H, Qian Z. Matrine reduces the secretion of exosomal circSLC7A6 from cancer-associated fibroblast to inhibit tumorigenesis of colorectal cancer by regulating CXCR5. Biochem Biophys Res Commun. 2020;527(3):638-45. 
141. Yang K, Zhang J, Bao C. Exosomal circEIF3K from cancer-associated fibroblast promotes colorectal cancer (CRC) progression via miR-214/ PD-L1 axis. BMC Cancer. 2021;21(1):933.

142. Li BL, Lu W, Qu JJ, Ye L, Du GQ, Wan XP. Loss of exosomal miR-148b from cancer-associated fibroblasts promotes endometrial cancer cell invasion and cancer metastasis. J Cell Physiol. 2019;234(3):2943-53.

143. Zhang N, Wang Y, Liu H, Shen W. Extracellular vesicle encapsulated microRNA-320a inhibits endometrial cancer by suppression of the HIF1alpha/NEGFA axis. Exp Cell Res. 2020;394(2):112113.

144. Nouraee N, Khazaei S, Vasei M, Razavipour SF, Sadeghizadeh M, Mowla SJ. MicroRNAs contribution in tumor microenvironment of esophageal cancer. Cancer Biomark. 2016;16(3):367-76.

145. Zhao G, Li H, Guo Q, Zhou A, Wang X, Li P, et al. Exosomal Sonic Hedgehog derived from cancer-associated fibroblasts promotes proliferation and migration of esophageal squamous cell carcinoma. Cancer Med. 2020;9(7):2500-13.

146. Zhang H, Deng T, Liu R, Ning T, Yang H, Liu D, et al. CAF secreted miR522 suppresses ferroptosis and promotes acquired chemo-resistance in gastric cancer. Mol Cancer. 2020;19(1):43.

147. Shi H, Huang S, Qin M, Xue X, Guo X, Jiang L, et al. Exosomal circ_0088300 Derived From Cancer-Associated Fibroblasts Acts as a miR-1305 Sponge and Promotes Gastric Carcinoma Cell Tumorigenesis. Front Cell Dev Biol. 2021;9:676319.

148. Wang X, Qin X, Yan M, Shi J, Xu Q, Li Z, et al. Loss of exosomal miR-3188 in cancer-associated fibroblasts contributes to HNC progression. J Exp Clin Cancer Res. 2019;38(1):151.

149. Zhang Z, Li X, Sun W, Yue S, Yang J, Li J, et al. Loss of exosomal miR-320a from cancer-associated fibroblasts contributes to HCC proliferation and metastasis. Cancer Lett. 2017;397:33-42.

150. You J, Li M, Cao LM, Gu QH, Deng PB, Tan Y, et al. Snail1-dependent cancer-associated fibroblasts induce epithelial-mesenchymal transition in lung cancer cells via exosomes. QJM. 2019;112(8):581-90.

151. Li YY, Tao YW, Gao S, Li P, Zheng JM, Zhang SE, et al. Cancer-associated fibroblasts contribute to oral cancer cells proliferation and metastasis via exosome-mediated paracrine miR-34a-5p. EBioMedicine. 2018;36:209-20.

152. Sun LP, Xu K, Cui J, Yuan DY, Zou B, Li J, et al. Cancer-associated fibroblast-derived exosomal miR-382-5p promotes the migration and invasion of oral squamous cell carcinoma. Oncol Rep. 2019;42(4):1319-28.

153. Chen JH, Wu ATH, Bamodu OA, Yadav VK, Chao TY, Tzeng YM, et al. Ovatodiolide Suppresses Oral Cancer Malignancy by Down-Regulating Exosomal Mir-21/STAT3/beta-Catenin Cargo and Preventing Oncogenic Transformation of Normal Gingival Fibroblasts. Cancers (Basel). 2019:12(1):56.

154. Principe S, Mejia-Guerrero S, Ignatchenko V, Sinha A, Ignatchenko A, Shi W, et al. Proteomic Analysis of Cancer-Associated Fibroblasts Reveals a Paracrine Role for MFAP5 in Human Oral Tongue Squamous Cell Carcinoma. J Proteome Res. 2018;17(6):2045-59.

155. Wang JW, Wu XF, Gu XJ, Jiang XH. Exosomal miR-1228 From CancerAssociated Fibroblasts Promotes Cell Migration and Invasion of Osteosarcoma by Directly Targeting SCAI. Oncol Res. 2019;27(9):979-86.

156. Guo H, Ha C, Dong H, Yang Z, Ma Y, Ding Y. Cancer-associated fibroblastderived exosomal microRNA-98-5p promotes cisplatin resistance in ovarian cancer by targeting CDKN1A. Cancer Cell Int. 2019;19:347.

157. Li W, Zhang X, Wang J, Li M, Cao C, Tan J, et al. TGFbeta1 in fibroblastsderived exosomes promotes epithelial-mesenchymal transition of ovarian cancer cells. Oncotarget. 2017;8(56):96035-47.

158. Shan G, Gu J, Zhou D, Li L, Cheng W, Wang Y, et al. Cancer-associated fibroblast-secreted exosomal miR-423-5p promotes chemotherapy resistance in prostate cancer by targeting GREM2 through the TGF-beta signaling pathway. Exp Mol Med. 2020;52(11):1809-22.

159. Lee E, Wang J, Yumoto K, Jung Y, Cackowski FC, Decker AM, et al. DNMT1 Regulates Epithelial-Mesenchymal Transition and Cancer Stem Cells. Which Promotes Prostate Cancer Metastasis Neoplasia. 2016;18(9):553-66.

160. Miyasaka A, Oda K, Ikeda Y, Sone K, Fukuda T, Inaba K, et al. PI3K/mTOR pathway inhibition overcomes radioresistance via suppression of the HIF1-alpha/VEGF pathway in endometrial cancer. Gynecol Oncol. 2015;138(1):174-80.

161. Groot AJ, Vooijs MA. The role of Adams in Notch signaling. Adv Exp Med Biol. 2012;727:15-36.
162. Zhao H, Yang L, Baddour J, Achreja A, Bernard V, Moss T, et al. Tumor microenvironment derived exosomes pleiotropically modulate cancer cell metabolism. Elife. 2016;5:e10250.

163. Cantor DI, Cheruku HR, Westacott J, Shin JS, Mohamedali A, Ahn SB. Proteomic investigations into resistance in colorectal cancer. Expert Rev Proteomics. 2020;17(1):49-65.

164. Lin JJ, Shaw AT. Resisting Resistance: Targeted Therapies in Lung Cancer. Trends Cancer. 2016;2(7):350-64.

165. Shagufta Al. Tamoxifen a pioneering drug: An update on the therapeutic potential of tamoxifen derivatives. Eur J Med Chem. 2018;143:515-31.

166. Mills JN, Rutkovsky AC, Giordano A. Mechanisms of resistance in estrogen receptor positive breast cancer: overcoming resistance to tamoxifen/aromatase inhibitors. Curr Opin Pharmacol. 2018;41:59-65.

167. Lux MP, Fasching PA, Schrauder MG, Hein A, Jud SM, Rauh C, et al. The PI3K Pathway: Background and Treatment Approaches. Breast Care (Basel). 2016;11(6):398-404.

168. Wang G, Li Z, Zhao Q, Zhu Y, Zhao C, Li X, et al. LincRNA-p21 enhances the sensitivity of radiotherapy for human colorectal cancer by targeting the Wnt/beta-catenin signaling pathway. Oncol Rep. 2014;31(4):1839-45.

169. Wortzel I, Dror S, Kenific CM, Lyden D. Exosome-Mediated Metastasis: Communication from a Distance. Dev Cell. 2019;49(3):347-60.

170. van der Leun AM, Thommen DS, Schumacher TN. CD8(+) T cell states in human cancer: insights from single-cell analysis. Nat Rev Cancer. 2020;20(4):218-32.

171. Reading JL, Galvez-Cancino F, Swanton C, Lladser A, Peggs KS, Quezada SA. The function and dysfunction of memory CD8(+) T cells in tumor immunity. Immunol Rev. 2018;283(1):194-212.

172. Chen L, Han X. Anti-PD-1/PD-L1 therapy of human cancer: past, present, and future. J Clin Invest. 2015;125(9):3384-91.

173. Chen G, Huang AC, Zhang W, Zhang G, Wu M, Xu W, et al. Exosomal PD-L1 contributes to immunosuppression and is associated with antiPD-1 response. Nature. 2018:560(7718):382-6.

174. Dou D, Ren X, Han M, Xu X, Ge X, Gu Y, et al. Cancer-Associated Fibroblasts-Derived Exosomes Suppress Immune Cell Function in Breast Cancer via the miR-92/PD-L1 Pathway. Front Immunol. 2020;1 1:2026.

175. McGranahan N, Swanton C. Clonal Heterogeneity and Tumor Evolution: Past, Present, and the Future. Cell. 2017;168(4):613-28.

176. Zhang Q, Higginbotham JN, Jeppesen DK, Yang YP, Li W, McKinley ET, et al. Transfer of Functional Cargo in Exomeres. Cell Rep. 2019;27(3):940-54.

177. Yin Z, Yu M, Ma T, Zhang C, Huang S, Karimzadeh MR, et al. Mechanisms underlying low-clinical responses to PD-1/PD-L1 blocking antibodies in immunotherapy of cancer: a key role of exosomal PD-L1. J Immunother Cancer. 2021;9(1):e001698.

178. Morrissey SM, Yan J. Exosomal PD-L1: Roles in Tumor Progression and Immunotherapy. Trends Cancer. 2020;6(7):550-8.

179. Wang J, Zeng H, Zhang H, Han Y. The role of exosomal PD-L1 in tumor immunotherapy. Transl Oncol. 2021;14(5):101047.

180. Yang Y, Li CW, Chan LC, Wei Y, Hsu JM, Xia W, et al. Exosomal PD-L1 harbors active defense function to suppress $T$ cell killing of breast cancer cells and promote tumor growth. Cell Res. 2018;28(8):862-4.

181. Yu P, Steel JC, Zhang M, Morris JC, Waitz R, Fasso M, et al. Simultaneous inhibition of two regulatory T-cell subsets enhanced Interleukin-15 efficacy in a prostate tumor model. Proc Natl Acad Sci U S A. 2012;109(16):6187-92.

182. Nishida-Aoki N, Tominaga N, Takeshita F, Sonoda H, Yoshioka Y, Ochiya T. Disruption of Circulating Extracellular Vesicles as a Novel Therapeutic Strategy against Cancer Metastasis. Mol Ther. 2017;25(1):181-91.

183. Datta A, Kim H, McGee L, Johnson AE, Talwar S, Marugan J, et al. High-throughput screening identified selective inhibitors of exosome biogenesis and secretion: A drug repurposing strategy for advanced cancer. Sci Rep. 2018;8(1):8161.

184. Ayala-Mar S, Donoso-Quezada J, Gonzalez-Valdez J. Clinical Implications of Exosomal PD-L1 in Cancer Immunotherapy. J Immunol Res. 2021;2021:8839978.

185. Luan X, Sansanaphongpricha K, Myers I, Chen H, Yuan H, Sun D. Engineering exosomes as refined biological nanoplatforms for drug delivery. Acta Pharmacol Sin. 2017;38(6):754-63.

186. Duan L, Xu L, Xu X, Qin Z, Zhou X, Xiao Y, et al. Exosome-mediated delivery of gene vectors for gene therapy. Nanoscale. 2021;13(3):1387-97. 
187. Yong T, Zhang $X$, Bie $N$, Zhang H, Zhang $X$, Li F, et al. Tumor exosomebased nanoparticles are efficient drug carriers for chemotherapy. Nat Commun. 2019;10(1):3838.

188. Koh E, Lee EJ, Nam GH, Hong Y, Cho E, Yang Y, et al. Exosome-SIRPalpha, a CD47 blockade increases cancer cell phagocytosis. Biomaterials. 2017;121:121-9.

189. Nie W, Wu G, Zhang J, Huang LL, Ding J, Jiang A, et al. Responsive Exosome Nano-bioconjugates for Synergistic Cancer Therapy. Angew Chem Int Ed Engl. 2020;59(5):2018-22.

190. Cheng LL, Zhang XZ, Tang JJ, Lv QJ, Liu J. Gene-engineered exosomesthermosensitive liposomes hybrid nanovesicles by the blockade of CD47 signal for combined photothermal therapy and cancer immunotherapy. Biomaterials. 2021;275:120964.

191. Zhao X, Wu D, Ma X, Wang J, Hou W, Zhang W. Exosomes as drug carriers for cancer therapy and challenges regarding exosome uptake. Biomed Pharmacother. 2020;128:110237.

192. Ahmed SF, Das N, Sarkar M, Chatterjee U, Chatterjee S, Ghosh MK. Exosome-mediated delivery of the intrinsic C-terminus domain of PTEN protects it from proteasomal degradation and ablates tumorigenesis. Mol Ther. 2015;23(2):255-69.

193. Putz U, Howitt J, Doan A, Goh CP, Low LH, Silke J, et al. The tumor suppressor PTEN is exported in exosomes and has phosphatase activity in recipient cells. Sci Signal. 2012;5(243):ra70.

194. Demory Beckler M, Higginbotham JN, Franklin JL, Ham AJ, Halvey PJ, Imasuen IE, et al. Proteomic analysis of exosomes from mutant KRAS colon cancer cells identifies intercellular transfer of mutant KRAS. Mol Cell Proteomics. 2013;12(2):343-55.

195. Languino LR, Singh A, Prisco M, Inman GJ, Luginbuhl A, Curry JM, et al. Exosome-mediated transfer from the tumor microenvironment increases TGF $\beta$ signaling in squamous cell carcinoma. Am J Transl Res. 2016:8(5):2432-7.

196. De Jaeghere EA, DH, De Wever O. Fibroblasts Fuel Immune Escape in the Tumor Microenvironment. Trends Cancer. 2019:5(11):704-23.

197. Popowski K, Lutz H, Hu S, George A, Dinh PU, Cheng K. Exosome therapeutics for lung regenerative medicine. J Extracell Vesicles. 2020;9(1):1785161.

\section{Publisher's Note}

Springer Nature remains neutral with regard to jurisdictional claims in published maps and institutional affiliations.

Ready to submit your research? Choose BMC and benefit from:

- fast, convenient online submission

- thorough peer review by experienced researchers in your field

- rapid publication on acceptance

- support for research data, including large and complex data types

- gold Open Access which fosters wider collaboration and increased citations

- maximum visibility for your research: over $100 \mathrm{M}$ website views per year

At BMC, research is always in progress.

Learn more biomedcentral.com/submissions 